Boezio et al., 2021

\title{
The developing epicardium regulates cardiac chamber morphogenesis by promoting cardiomyocyte growth
}

$\underline{\text { Giulia L. M. Boezio }}^{1,2,3}$, Josephine Gollin ${ }^{1,4}$, Shengnan Zhao ${ }^{1}$, Rashmi Priya ${ }^{1,5}$, Shivani Mansingh $^{1,6}$, Stefan Guenther ${ }^{7}$, Nana Fukuda ${ }^{1}$, Felix Gunawan ${ }^{1,2}$, Didier Y. R. Stainier ${ }^{1,2}$ *

${ }^{1}$ Department of Developmental Genetics, Max Planck Institute for Heart and Lung Research, Bad Nauheim, 61231, Germany

${ }^{2}$ DZHK German Centre for Cardiovascular Research, Partner Site Rhine-Main, D-61231 Bad Nauheim, Germany 61231

${ }^{3}$ Present address: The Francis Crick Institute, Developmental Dynamics Laboratory, London, United Kingdom

${ }^{4}$ Present address: Williams College, Department of Biology, Williamstown, MA, USA

${ }^{5}$ Present address: The Francis Crick Institute, Organ Morphodynamics Laboratory, London, United Kingdom

${ }^{6}$ Present address: Biozentrum, University of Basel, Basel, Switzerland

${ }^{7}$ Bioinformatics and Deep Sequencing Platform, Max Planck Institute for Heart and Lung Research, Bad Nauheim, 61231, Germany

*Correspondence to:

Didier.Stainier@mpi-bn.mpg.de

\begin{abstract}
The epicardium, the outermost layer of the heart, is an important regulator of cardiac regeneration. However, a detailed understanding of the crosstalk between the epicardium and myocardium during development requires further investigation. Here, we generated three models of epicardial impairment in zebrafish by mutating the transcription factor genes $t c f 21$ and wt $1 a$, and by ablating tcf $21^{+}$epicardial cells. Notably, all three epicardial-impairment models exhibit smaller ventricles. We identified the initial cause of this phenotype as defective cardiomyocyte growth, resulting in reduced cell surface and volume. This failure of cardiomyocytes to grow is followed by decreased proliferation and increased abluminal extrusion. By temporally manipulating its ablation, we show that the epicardium is required to support ventricular growth during early cardiac morphogenesis. By transcriptomic profiling of sorted epicardial cells, we identified reduced expression of FGF and VEGF ligand genes in $t c f 21^{-/}$hearts, and pharmacological inhibition of these signaling pathways partially recapitulated the ventricular growth defects. Thus, the analysis of these epicardial-impairment models further elucidates the distinct roles of the epicardium during cardiac morphogenesis and the signaling pathways underlying epicardialmyocardial crosstalk.
\end{abstract}


Boezio et al., 2021

\section{Introduction}

The epicardium is the last layer to incorporate into the heart during development. Epicardial cells (EpiCs) delaminate from the extra-cardiac proepicardial organ (PEO) and attach to the naked myocardium as free-floating cells due to the physical properties of the pericardial fluid (Rodgers et al., 2008; Peralta et al., 2013). The epicardium forms a mesothelial layer that completely envelops the heart, then undergoes epithelial-to-mesenchymal transition (EMT) and gives rise to various epicardial derived cells (EPDCs) (Smith et al., 2011; Acharya et al., 2012; Smits et al., 2018). While the epicardium becomes dormant after undergoing EMT, it reactivates after cardiac injury and upregulates developmental genes as well as new gene regulatory networks (Weinberger et al., 2021), and it rapidly regenerates (Masters and Riley, 2014; Cao and Poss, 2018).

The epicardium has received great attention due to its ability to differentiate into a multitude of cell types during cardiac repair and to its role as a source of paracrine signals that promote wound healing (Masters and Riley, 2014; Cao and Poss, 2018). However, a detailed understanding of the epicardial-myocardial crosstalk during development has proven more elusive. As the few identified factors involved in epicardial-myocardial signaling, including components of the fibroblast growth factor (FGF) and insulin growth factor (IGF) signaling pathways, are expressed in developmental and regenerative contexts (Pennisi et al., 2003; Lavine et al., 2005; Brade et al., 2011; Li et al., 2011; Vega-Hernandez et al., 2011), identifying the processes underlying epicardial-myocardial crosstalk during development has important implications for cardiac repair.

Defects in epicardial coverage consistently result in a common myocardial phenotype - small, underdeveloped ventricles. Ablation of the PEO in chicken embryos causes reduced cardiac size and occasional ventricular bulging (Manner, 1993; Pennisi et al., 2003; Manner et al., 2005; Takahashi et al., 2014). Similarly, mutations in several epicardial-enriched genes, including those encoding the transcription factors TCF21 and WT1, abrogate epicardial coverage, leading to a reduction in ventricular size (Moore et al., 1999; Acharya et al., 2012). Most studies to date have concluded that the major role of the epicardium is to promote CM proliferation (Pennisi et al., 2003; Lavine et al., 2005; Li et al., 2011) and to contribute to the ventricular mass by giving rise to EPDCs such as fibroblasts (Mahtab et al., 2009; Acharya et al., 2012). Notably, a few studies have started to challenge the view that the sole function of the epicardium is to regulate $\mathrm{CM}$ cell cycle (Eid et al., 1992; Kastner et al., 1994; Takahashi et al., 2014), but they have so far been limited to using in vitro explants or fixed tissue sections. Deeper investigation of epicardial function in promoting myocardial growth requires a model in which the cellular phenotypes can be experimentally followed in 4 dimensions.

Here, we generated three models of epicardial impairment in zebrafish larvae by mutating the transcription factor genes $t c f 21$ and $w t 1 a$, and by ablating EpiCs. Leveraging the advantages of these newly established models and the amenability of zebrafish to live imaging at 3D resolution, we identified a novel role for the epicardium in promoting CM growth and determined the timewindow when this epicardium to myocardium interaction occurs. We also generated a 
Boezio et al., 2021

transcriptomic dataset of epicardial-enriched factors to identify molecules important for this crosstalk. Focusing on $f g f 24$ and vegfaa, we provide evidence that they are epicardial-enriched regulators of ventricular growth.

\section{Results \\ Generation of three zebrafish epicardial-impairment models}

In zebrafish, EpiCs start adhering to the myocardial wall around 52-56 hours post fertilization (hpf), and cover the entire ventricle by 96-120 hpf (Fig. 1A) (Peralta et al., 2014). To study the epicardial-myocardial crosstalk, we generated three different zebrafish models with impaired epicardial coverage. First, we mutated $t c f 21$ and wtla (Fig. S1C), two transcription factor genes enriched in the epicardium (Fig. S1A, B) (Serluca, 2008; Liu and Stainier, 2010; Peralta et al., 2014)). Our $t c f 21$ deletion allele contains a frameshift in the coding sequence, leading to a predicted truncated protein with an incomplete DNA-binding domain (Fig. S1C), while the mutation does not affect the stability of the mutant mRNA (Fig. S1 D). Conversely, our wt la promoter deletion leads to a complete absence of wtla mRNA (Fig. S1C, E). In mouse, the lack of either transcription factor leads to impaired epicardial coverage, but its impact on myocardial development is poorly understood (Moore et al., 1999; Acharya et al., 2012). We observed that in zebrafish, mutations in $t c f 21$ and $w t 1 a$ also lead to a reduction of $\operatorname{Tg} B A C\left(t c f 21\right.$ :NLS-EGFP) ${ }^{+}$ (hereafter referred to as $t c f 21^{+}$) EpiCs on the ventricular wall, as evidenced at $54 \mathrm{hpf}$ and -even more prominently- at 76 and 100 hpf (Fig. 1B-H). However, whereas wtla mutants exhibit a complete absence of $\operatorname{tcf} 21^{+}$EpiCs on the ventricular wall, the epicardial coverage reduction in tcf 21 mutants is variable (Fig. 1I). This phenotypic variability is likely not due to the $t c f 21$ mutation leading to a hypomorphic allele, as non-cardiac phenotypes previously identified in $t c f 21$ mutants, including the lack of head muscles (Nagelberg et al., 2015; Burg et al., 2016), are observed with complete penetrance in our $t c f 21$ mutants ( $>300$ larvae). Notably, the number of outflow tract (OFT) $t c f 21^{+}$EpiCs appears unaffected in both mutants (Fig. 1J), likely due to the different origin of this epicardial population (Perez-Pomares et al., 2003; Weinberger et al., 2020). Second, to establish a model in which epicardial coverage can be impaired in a specific time window, we used the previously described nitroreductase/metronidazole (NTR/MTZ) system (Curado et al., 2007; Pisharath et al., 2007; Curado et al., 2008). By treating TgBAC(tcf21:mCherry-NTR) (Wang et al., 2015) embryos $\left(\mathrm{NTR}^{+}\right.$) with MTZ, we could ablate nearly all $t c f 21^{+}$cells before the epicardium covers the ventricle (52-100 hpf; Fig. 1K-M), thereby establishing an inducible system which complements our two mutant models. Using the panepicardial marker Caveolin1 (Cao et al., 2016), we confirmed that $\operatorname{TgBAC}(\operatorname{tcf} 21$ :NLS-EGFP) expression is a reliable marker for all EpiCs, and that the loss of $t c f 21^{+}$cells in our models is due to an absence of EpiCs and not to the loss of $\operatorname{Tg} B A C(\operatorname{tcf} 21$ :NLS-EGFP) expression. Caveolin1 immunostaining was only present in "escaper" ventricular $t c f 21^{+}$EpiCs in $t c f 21^{-/}$hearts, and 
Boezio et al., 2021

around the OFT in all three models (Fig. S1F-I'). Altogether, these three distinct epicardialimpairment models constitute a complementary set of reagents to study the effects of epicardial impairment on cardiac morphogenesis. Moreover, using the genetic models generated here as well as others, it will be interesting to investigate how Wt1a and Tcf21 regulate epicardial development.

\section{Impairment in cardiomyocyte growth becomes evident before reduced cardiomyocyte} proliferation when epicardial cells are lost

We next aimed to determine how epicardial impairment affects ventricular morphogenesis. Starting at $96 \mathrm{hpf}$, we observed pericardial edema in $t c f 21^{-/}$, wt $1 \mathrm{a}^{-/-}$and $\mathrm{NTR}^{+}$MTZ-treated larvae (Fig. S1J-M), together with impaired ventricular fractional shortening starting at $100 \mathrm{hpf}$ (Fig. S2A). The cardiac ventricle in all epicardial-impairment models was also approximately $30 \%$ smaller than in wild type (WT; Fig. 2A-D, S2B-E). Interestingly, from 76 to $100 \mathrm{hpf}$, we observed that the wild-type ventricle grew on average by $36.4 \%$ in volume, whereas the mutant ventricle started with a comparable volume at $76 \mathrm{hpf}$ but failed to enlarge over time (Fig. 2E). Increase in organ size is driven by hypertrophic (increase in cell size) and hyperplastic (increase in cell number) growth. The first phenotype we observed between control and epicardialimpairment models was in the CM apical area. Although the average apical area of compact layer CMs was comparable in WT and mutant larvae at $76 \mathrm{hpf}$, it was significantly smaller in mutant CMs compared to WT at $100 \mathrm{hpf}$ (Fig. 2F, S2F). To assess the volumetric growth of individual compact layer CMs over time, we tracked single CMs in $\operatorname{tcf} 21^{+/+}$and $t c f 21^{-/}$hearts by mosaic expression of $\operatorname{Tg}(\mathrm{myl}$ : $\mathrm{mScarlet})$. Strikingly, $t c f 21^{+/+} \mathrm{CM}$ volume increased by $26.8 \%$ between 76 and 100 hpf, while $t c f 21^{-/} \mathrm{CM}$ volume did not significantly change (+1.4\%) (Fig. 2G-I). Our data are, to our knowledge, the first to correlate an increase in $\mathrm{CM}$ cell volume with ventricular growth, and to uncover a requirement for the epicardium in promoting $\mathrm{CM}$ cell growth during cardiac development.

While the epicardium has not been previously linked with CM hypertrophic growth, it has been implicated in promoting CM proliferation (Pennisi et al., 2003; Lavine et al., 2005; Li et al., 2011). We therefore assessed the number of proliferating CMs at $82 \mathrm{hpf}$, a time point before the growth defects can be observed, by counting the number of Venus-Gmnn ${ }^{+} \mathrm{CMs}$ (cells in the S/G/M phases (Sugiyama et al., 2009; Choi et al., 2013). We observed no significant difference between control and $\mathrm{NTR}^{+}$MTZ-treated larvae (Fig. 2K-M). We also counted the number of ventricular CMs, and they increased by a similar proportion $(\approx 30 \%)$ in WT larvae and in larvae from all three models between 76 and 100 hpf (Fig. 2J), resulting in comparable numbers of CMs at all time points analyzed (Fig. S2G). Interestingly, at $105 \mathrm{hpf}$, a time point subsequent to the 
Boezio et al., 2021

111 appearance of CM size defects, we observed a severe reduction in the number of Venus-Gmnn ${ }^{+}$

$112 \mathrm{CMs}_{\mathrm{C}} \mathrm{NTR}^{+}$MTZ-treated larvae compared with controls (-48.5\%; Fig. 2N). These defects in

$113 \mathrm{CM}$ proliferation may thus be a consequence of the initial impairment in CM growth. In support

114 of this interpretation, eukaryotic cell cycle progression is known to depend on cell growth

115 (Jorgensen and Tyers, 2004), and a multitude of cell types, including CMs, expand in size prior to

116 dividing (Son et al., 2015; Zlotek-Zlotkiewicz et al., 2015; Uribe et al., 2018). In addition, we

117 observed CM extrusion away from the cardiac lumen in the three epicardial-impairment models

118 (Fig. S3A-F'), consistent with previous reports (Manner et al., 2005; Rasouli et al., 2018). We

119 hypothesize that in the absence of the epicardium, excessive cellular density -as observed by

120 reduced inter-nuclear distance in the epicardial-impairment models (Fig. S3G-I)- drives the

121 aberrant extrusion of a few CMs. However, this CM extrusion in the epicardial-impairment

122 models only plays a minor role in their reduced ventricular size.

123 Altogether, our observations uncover a previously unidentified role for the epicardium in

124 promoting the initial stages of $\mathrm{CM}$ growth, which subsequently affects CM proliferation and

125 ventricular growth.

Epicardial cells are required and sufficient for ventricular cardiomyocyte growth in a

\section{8 restricted early time window}

129 To further analyze the dependency of CM growth on the epicardium, we tested whether rescuing 130 the epicardial coverage was sufficient to improve ventricular growth. Leveraging the temporal 131 versatility of the NTR/MTZ system, we ablated the epicardium specifically from 52 to $100 \mathrm{hpf}$ 132 and then washed out the MTZ; we first confirmed that the EpiCs recover by $144 \mathrm{hpf}$ (Fig. 3A-C), 133 as previously reported (Wang et al., 2015). Strikingly, epicardial restoration was sufficient to 134 ameliorate the cardiac growth defects in MTZ-treated larvae (Fig. 3B'-D).

135 Previous studies investigating the consequences of reduced epicardial coverage have used genetic 136 models or physical ablation of the PEO, but the constitutive lack of epicardium fails to pinpoint 137 the time window in which EpiCs promote myocardial development. As mentioned above, we 138 identified the 52-100 hpf window to be crucial for epicardial-myocardial interactions, which 139 coincides with the period of epicardial attachment. We then tested the effects of epicardial 140 ablation between 96 and 144 hpf (Fig. 3A); surprisingly, while epicardial ablation appeared quite 141 effective (Fig. 3 E, F), we observed no obvious morphological defects in ventricular morphology 142 or size (Fig. 3D-F').

143 These results suggest that epicardial-myocardial crosstalk is necessary to regulate ventricular 144 volume during 52-100 hpf, but dispensable once epicardial coverage is complete (96 hpf). We 145 propose that, from $96 \mathrm{hpf}$ onwards, the CMs continue to grow due to epicardial-independent 
Boezio et al., 2021

146 intrinsic or extrinsic cues. Therefore, at later stages, the epicardium might assume a different

147 function, including preparing for the onset of EMT. Future investigations of later epicardial

148 function during cardiac development (e.g., at the onset of EMT and EPDCs formation) will

149 greatly benefit from the temporal versatility of this NTR/MTZ model.

\section{Epicardial-derived secreted factors promote ventricular cardiomyocyte growth}

152 Next, we aimed to understand how the epicardium modulates CM growth. The epicardium is an 153 important signaling center during development and regeneration (Quijada et al., 2020).

154 Nonetheless, the appearance of extruding CMs in epicardial-deficient larvae (Fig. S3), which was 155 also observed following PEO ablation in chick (Manner et al., 2005), raised questions as to 156 whether the epicardium primarily acts as a physical barrier to preserve myocardial integrity. To 157 further investigate the role of the epicardium as a mechanical support and/or a signaling source, 158 we focused on the sizable fraction of $t c f 21^{-/}$hearts that exhibited substantial epicardial coverage 159 on their ventricle (Fig. 1H; Fig. S4A-C). We first observed that these mutants still displayed 160 defects in ventricular size that were comparable with those in $t c f 21^{-/}$hearts devoid of epicardial 161 coverage (Fig. S4A-C). We found no significant correlation between the number of ventricular 162 EpiCs and ventricular volume (Fig. S4D), or the number of extruding CMs (Fig. S4F). Notably, we also observed that some extruding CMs were covered by EpiCs (Fig. S4, E'), suggesting that the physical presence of EpiCs alone does not prevent CM extrusion.

165 To identify epicardial factors necessary for CM growth, we compared the transcriptomes of sorted $\operatorname{tcf} 21^{+/+}$and $t c f 21^{-/}$EpiCs and CMs at 96 hpf (Fig. 4A; Supplementary Tables 2 and 3). To minimize bias in the analyses, we selected $t c f 21^{-/-}$larvae that exhibited a wild-type-like ventricular epicardial coverage and collected the same number of EpiCs from the two genotypes. We first analyzed the genes expressed in the two wild-type populations by RNA-seq and confirmed the expression of cell-specific markers, including postnb, wt1a, colla2, cav1, aldh1a2 in EpiCs and ttn.1, ttn.2, myh7, myh6 in CMs.

We focused on epicardial-derived secreted factors that potentially mediate this epicardialmyocardial crosstalk. Amongst the factors enriched in the EpiCs compared to CMs are members of the FGF, IGF, transforming growth factor (TGF)- $\beta$, and platelet-derived growth factor (PDGF) pathways (Fig. 4B; Supplementary Table 3). These pathways are important for epicardialmyocardial crosstalk in mammals (Olivey and Svensson, 2010; Li et al., 2017), suggesting that the molecular regulators of this crosstalk are similar in zebrafish. Amongst the downregulated secreted factors in $t c f 21^{-/}$EpiCs are $F G F$ and $V E G F$ ligand genes, including $f g f 10 a$, $f g f 24$, vegfaa, vegfba (Fig. 4B, C; Supplementary Table 3). fgf24 and vegfaa (Fig. 4C, S5A), in particular, are the $F G F$ and $V E G F$ ligand genes with the highest epicardial 
Boezio et al., 2021

181 expression in our dataset and the only ones significantly downregulated ( $P$ adj. $<0.05$;

182 Supplementary Table 3). The FGF pathway mediates epicardial-myocardial crosstalk in mouse

183 and chicken embryos, where it is primarily known for its role in promoting CM proliferation

184 (Pennisi et al., 2003; Lavine et al., 2005). By in situ hybridization, we observed $f g f 24$ expression

185 in $76 \mathrm{hpf}$ hearts including in the epicardium (Fig. S5B, B'). On the other hand, Vegfaa promotes

186 angiogenesis and coronary vessel formation (Liang et al., 2001; Wu et al., 2012; Marin-Juez et al.,

187 2016; Rossi et al., 2016), but its role in the developing epicardium has not been investigated until

188 recently (Bruton et al., 2021). We observed that vegfaa expression in the developing heart

189 appears to be initially limited to the epicardium until 100 hpf (Fig. S5C-D'; (Bruton et al.,

190 2021)), at which point it also becomes expressed in the endocardium (Karra et al., 2018). The

191 epicardial enrichment of $f g f 24$ and vegfaa ( $\log 2 \mathrm{FC}:+4,77$ and $+3,38$, respectively), as well as

192 their downregulation in $t c f 21^{-/}$EpiCs led us to hypothesize that epicardial-derived Fgf 24 and

193 Vegfaa mediate signaling to the myocardium. To test this hypothesis, we first assessed the

194 activation of the mitogen-activated protein kinase (MAPK)/extracellular regulated kinase (ERK)

195 pathway, a downstream effector of both FGF and VEGF signaling, in CMs. To do so, we

196 generated a transgenic line, $T g(m y l 7: E R K-K T R$-Clover-P2A-H2B-mScarlet), to monitor ERK

197 activation through a kinase translocation reporter (de la Cova et al., 2017; Mayr et al., 2018;

198 Okuda et al., 2020) (Fig. 4D). Following MTZ treatment between 52 and $80 \mathrm{hpf}$,

199 TgBAC(tcf21:mCherry-NTR);Tg(myl7:ERK-KTR-Clover-P2A-H2B-mScarlet) hearts devoid of

200 epicardium exhibited a significantly increased number of CMs with inactive ERK signaling compared with control hearts (Fig. 4D-F). In addition, we used BGJ398 (De Simone et al., 2021) and SKLB1002 (Zhang et al., 2011) to inhibit the FGF and VEGF signaling pathways, respectively, from 65 to $100 \mathrm{hpf}$. Larvae treated with these compounds recapitulated the smaller ventricle phenotype. FGF inhibition affected ventricular volume without causing any changes in CM number, whereas the VEGF inhibitor led to a mild but significant decrease in ventricular CMs $(-10 \%$; Fig. 4G-K). It is likely that a global inhibition of the VEGF pathway leads to a stronger

207 phenotype compared to the epicardial-specific downregulation of vegfaa in $\operatorname{tcf} 21^{-/}$hearts, and/or 208 that SKLB1002 affects additional signaling pathways. expressed in zebrafish CMs and downregulated in $t c f 21^{-/-} \mathrm{CMs}$, as per our transcriptomic datasets

211 (Supplementary Table 2). We speculate that the downregulation of Fgfr4 in CMs might be caused

212 by feedback loops caused by the reduction in Fgf24. On the other hand, Vegfaa is not known to 213 bind receptors prominently expressed in CMs, but binds Vegfr2/Kdrl, which is enriched in EpiCs. 214 Therefore, Vegfaa potentially signals in an autocrine manner, similar to retinoic acid (Stuckmann 215 et al., 2003; Brade et al., 2011), and regulates the production of other signaling molecules.

216 Otherwise, it was recently proposed that the epicardial expression of vegfaa (in response to 
Boezio et al., 2021

217 macrophage activation) regulates Notch activity in the endocardium, which -in turn- signals to

218 CMs (Bruton et al., 2021). Further studies will address the molecular mechanisms by which these

219 signaling pathways mediate epicardial-myocardial crosstalk to promote ventricular

220 morphogenesis.

221 Alternatively, we cannot exclude the possibility that ECM-related components secreted by the

222 epicardium play a role in maintaining CM homeostasis and promoting their growth. In particular,

223 we observed the downregulation of several ECM component genes, including col6a1/2, col4al/2,

$224 \quad l a m a 5$ and haplnla/b.

225 Altogether, our data uncover a previously unappreciated requirement for the epicardium in

226 promoting CM growth at the cellular and tissue levels, which takes place prior to its previously

227 reported role in stimulating CM proliferation. Moreover, we provide evidence that this inter-

228 tissue crosstalk is mediated by the FGF and VEGF pathways. We propose that the three

229 epicardial-impairment models used in this study provide genetically tractable, and in one case

230 temporally manipulable, systems that complement existing models to deepen our understanding of

231 the cellular and molecular processes involved in epicardial-myocardial crosstalk during cardiac

232 development. 
Boezio et al., 2021

\section{Data and Software Availability}

235 The RNA-seq data reported in this paper have been deposited in the Gene Expression Omnibus

236 (GEO) database https://www.ncbi.nlm.nih.gov/geo/query/acc.cgi?acc=GSE174505 (accession

237 GSE174505). (Reviewer token: wbydmsugdfmfhch).

\section{Acknowledgments}

240 This work was supported by funds from the Max Planck Society to D.Y.R.S., a European

241 Molecular Biology Organization (EMBO) Advanced Fellowship (ALTF 642-2018) and a

242 Canadian Institute for Health Research Fellowship (293898) to F.G., and an EMBO fellowship

243 (LTF 1569-2016), a Humboldt fellowship and a Cardio-Pulmonary Institute Grant (EXC 2026,

244 project ID 390649896) to R.P. We would like to thank Matteo Perino for help with the RNA-seq

245 analyses and critical comments on the manuscript, Ann Atzberger and Khrievono Kikhi for help

246 with the FACS experiments, Michelle Collins, Alessandra Gentile, Srinivas Allanki and Hadil El-

247 Sammak for valuable discussions and comments on the manuscript, Dr. Radhan Ramadass for

248 expert help with microscopy, Helen Allmendinger for experimental assistance, and all the fish

249 facility staff for technical support.

\section{Author contributions}

252 Conceptualization, G.L.M.B, F.G., and D.Y.R.S.; Methodology, G.L.M.B, F.G., N.F., S.G., R.P., 253 and S.M; Validation, G.L.M.B.; Formal Analysis, G.L.M.B. and S.G.; Investigation, G.L.M.B., 254 S.Z., J.G., and S.G.; Writing - Original Draft, G.L.M.B., F.G., and D.Y.R.S.; Writing 255 Reviewing \& Editing, all; Visualization, G.L.M.B.; Supervision, F.G. and D.Y.R.S; Project 256 Administration, D.Y.R.S.; Funding Acquisition, D.Y.R.S. 
Boezio et al., 2021

\section{Figure legends}

\section{Figure 1: The transcription factors Tcf21 and Wt1a are required for epicardial} attachment to the ventricle

A) Schematic representation of the epicardial coverage of the zebrafish embryonic and larval heart. B-G) Confocal images of 76 (B-D) and 100 (E-G) hpf $\operatorname{TgBAC}(\operatorname{tcf} 21: N L S-E G F P)$; $\operatorname{Tg}(m y l 7: m C h e r r y-C A A X)$ larvae. H) Schematics of the epicardial coverage in $100 \mathrm{hpf}$ WT, $t c f 21^{-/-}$and $w t l a^{-/-}$larvae. Grey, myocardium; green, EpiCs. I-J) Quantification of $t c f 21^{+}$ EpiCs attached to the ventricular myocardium $(\mathrm{H})$ and the OFT (I). The colors of WT dots refer to $t c f 21^{+/+}$(red) and $w t 1 a^{+/+}$(orange) siblings. Mean $\pm \mathrm{SD}$; $P$ values from $t$ - or MannWhitney tests (following normality test) compared with $+/+$ siblings of each genotype. K) Epicardial ablation protocol using the NTR/MTZ system. L-M) Confocal images of $100 \mathrm{hpf}$ TgBAC(tcf21:mCherry-NTR); $\operatorname{Tg}(m y l 7: E G F P-H R A S)$ hearts, showing the absence of EpiCs post MTZ treatment (M), compared with DMSO-treated larvae (L). WT, wild types; A, atrium; V, ventricle; OFT, outflow tract; PEO, proepicardial organ.

\section{Figure 2: Impaired epicardial coverage affects ventricular cardiomyocyte size increase} and ventricular growth

A-D) Confocal images of $100 \mathrm{hpf} \mathrm{WT}, t c f 21^{-/}$, wt $1 \mathrm{a}^{-/}$, and $\operatorname{TgBAC}(t c f 21: \mathrm{mCherry}-N T R)^{+}$ $\left(\mathrm{NTR}^{+}\right)$MTZ-treated larvae, exhibiting reduced ventricular size. E, F) Change in ventricular volume (E) and CM apical area (F) from 76 to $100 \mathrm{hpf}$ in WT, $t c f 21^{-/-}$and $w t 1 a^{-/}$larvae. G) Measurement of individual CM volume increase in percentage between 76 and $100 \mathrm{hpf}$, as measured through the myl7:mScarlet signal; large dots, average per larva; small dots, individual CMs. Mean $\pm \mathrm{SD} ; P$ values from $t$-test comparing the averages per larva. H-I') Confocal images of $\operatorname{Tg}(m y l 7: B F P-C A A X) ; t c f 21^{+/+}$or $t c f 21^{-/-}$larva at 76 and $100 \mathrm{hpf}$ (same larvae shown), injected with myl7:mScarlet DNA to label individual CMs; (H'-I') 3D surface rendering of individual CMs at the two time points. J) Changes in ventricular CM numbers from 76 to 100 hpf in WT (or NTR'), $t c f 21^{-/-}, w t 1 a^{-/-}$and $\mathrm{NTR}^{+}-\mathrm{MTZ}$ treated larvae. K-N) Confocal images and quantification of $m y l 7: m V e n u s-G m n n^{+} \mathrm{CMs}$ in $82(\mathrm{~K}-\mathrm{M})$ and $105(\mathrm{~N})$ hpf control (NTR-) and $\mathrm{NTR}^{+}$MTZ-treated larvae. E, F, J) Mean $\pm \mathrm{SD} ; P$ values from OneWay ANOVA amongst the three different genotypes at the same time-point (above the graph), or $t$-tests comparing the two different time-points within the same genotype (on the dotted lines). Single data points are shown in Figure S2. M, N) Median (solid line) and quartiles (dashed lines); $P$ values from $t$-tests. WT, wild types; A, atrium; V, ventricle. 
Boezio et al., 2021

Figure 3: Epicardial cells are required for ventricular cardiomyocyte growth during early cardiac morphogenesis, but are dispensable at later timepoints

A) Schematic of the MTZ treatment protocol. B-C') Confocal images of $144 \mathrm{hpf} \operatorname{Tg}(\mathrm{myl}$ : EGFP-HRAS); TgBAC(tcf21:mCherry-NTR) DMSO and MTZ-treated larvae. Green, 3D reconstruction of epicardial coverage, showing a partial recovery of EpiCs in 52-96 hpf MTZ

D) Quantification of ventricular volume at $144 \mathrm{hpf}$ following epicardial regeneration or late epicardial ablation. E-F') Confocal images of $144 \mathrm{hpf} T g(m y l 7: E G F P$ HRAS); TgBAC(tcf21:mCherry-NTR) DMSO and MTZ-treated larvae. Green, 3D reconstruction of epicardial coverage, showing the lack of epicardium in 96-144 hpf MTZventricle.

Figure 4: Epicardial-enriched $F G F$ and $V E G F$ ligand genes in epicardial-myocardial crosstalk

A) RNA-seq from $t c f 21^{+}$and $m y l 7^{+}$cells from $96 \mathrm{hpf} t c f 21^{+/+}$and $t c f 21^{-/-}$hearts. B) Heatmap of zebrafish secreted factor genes in $t c f 21^{+/+}$and $t c f 21^{-/}$EpiCs and CMs, showing Z scores normalized per row. The genes highlighted in bold are differentially expressed between $t c f 21^{+/+}$and $t c f 21^{-/-}$EpiCs $(\log 2 \mathrm{FC}<|0.7|, P$ adj. $<0.05)$.

C) Venn diagram denoting the intersection between secreted factor genes in the zebrafish genome and genes that are downregulated $(\log 2 \mathrm{FC}<-0.7, P$ adj. $<0.05)$ in $t c f 21^{-/-}$EpiCs. D-F) Confocal images $(\mathrm{D}, \mathrm{E})$ and quantification (F) of $82 \mathrm{hpf} \operatorname{Tg}($ myl7:ERK-KTR-Clover-P2A-H2B-mScarlet) ventricles in control (NTR') and $\operatorname{TgBAC}(t c f 21: m C h e r r y-N T R)\left(\mathrm{NTR}^{+}\right)$larvae treated with MTZ. White arrowheads point to CMs with nuclear Clover (inactive ERK), quantified in F. G-K) Confocal images (G-I'), quantification of ventricular volume (J) and CM numbers (K) of 100 hpf larvae treated with FGFR (BGJ398) and VEGFR (SKLB1002) inhibitors starting at 65 hpf. A, atrium; V, ventricle.

Figure S1: Transcription factors Tcf21 and Wt1a are crucial for cardiac development

A, B) In situ hybridization showing the expression of tcf21(A) and wtla (B) in $76 \mathrm{hpf}$ hearts. MF20 immunostaining (green) labels the myocardium (dashed lines); arrowheads point to the and predicted Tcf21 mutant protein, highlighting the bHLH (red, Tcf21) and Zn finger (orange, Wtla) domains. Yellow star indicates the CRISPR/Cas9-induced mutation site; the 
Boezio et al., 2021

black rectangle represents new sequence downstream of the frameshift-inducing mutation. The wtla mutation targets the promoter region and does not affect the coding sequence. D, E) $t c f 21$ (D) and $w t 1 a(\mathrm{E}) \mathrm{mRNA}$ levels in $96 \mathrm{hpf} t c f 21^{+/+}, t c f 21^{-/-}, w t 1 a^{+/+}$, and $w t 1 a^{-/-}$larvae; means $\pm \mathrm{SD} ; P$ values from Mann Whitney tests; $C t$ values are listed in Supplementary Table 1. F-I') Confocal images of $100 \mathrm{hpf}$ hearts immunostained for Caveolin1 (Cav1). Cav1 immunostaining is present only in "escaper" ventricular $t c f 21^{+}$EpiCs (yellow arrowheads, $t c f 21^{-/-}$) and in the OFT (white arrowheads). J-M) $96 \mathrm{hpf} t c f 2 \mathrm{1}^{-/}, w t 1 \mathrm{a}^{-/}$, and NTR ${ }^{+}$MTZtreated larvae exhibit pericardial edema (arrowheads) and lack of swim bladder inflation (asterisks). A, atrium; V, ventricle; OFT, outflow tract; bHLH, basic helix-loop-helix; Zn, zinc.

\section{Figure S2: Epicardial impairment affects ventricular size, but not ventricular} cardiomyocyte number

A-C) Confocal images of $76 \mathrm{hpf} \mathrm{WT}, t c f 21^{-/}$, and $w t 1 a^{-/-}$larvae, all exhibiting a similar ventricular size. D-E) Quantification of fractional shortening (D) and ventricular volume (E) in WT, mutant and $\mathrm{NTR}^{+}$MTZ-treated larvae; the graph in E relates to Figure 2E, showing the single data points. F) CM apical area in WT, $t c f 21^{-/-}$, and $w t 1 a^{-/-}$larvae; related to Figure 2F. Violin plot represents the distribution of individual CMs (n); dots represent the average per larva (N). G) Ventricular CM numbers in WT, mutant and $\mathrm{NTR}^{+}$MTZ-treated larvae, showing individual data points; related to Figure 2 J. A, B, F, G) The colors of wild-type dots refer to $t c f 21^{+/+}$(red), $w t 1 a^{+/+}$(orange), and $\mathrm{NTR}^{+}$MTZ-treated (grey) siblings. Median and quartiles $(\mathrm{A}, \mathrm{B}, \mathrm{G})$, or mean $\pm \mathrm{SD}(\mathrm{F}) ; P$ values from $t$ - or Mann-Whitney tests (following normality test), compared with the WT/control siblings of each genotype/treatment. WT, wild types; A, atrium; V, ventricle; N, number of larvae; n, number of CMs.

\section{Figure S3: Impaired epicardial coverage causes abluminal cardiomyocyte extrusion} A-D) 3D surface rendering of $96 \mathrm{hpf} \operatorname{Tg}(m y l 7: m C h e r r y-C A A X)(\mathrm{A}-\mathrm{C})$ and $\operatorname{Tg}(m y l 7: E G F P$ $H R A S)$ (D) hearts. Arrowheads point to extruding CMs. E) Quantification of CM extrusions at 76 and 96 hpf. F, F') Single-plane images of $76 \mathrm{hpf} \operatorname{Tg}(m y l 7: m C h e r r y-C A A X) t c f 21^{-/-}$ heart. Arrowheads point to extruding CMs. G-I) Confocal images and quantification of the CM inter-nuclear distance in $100 \mathrm{hpf} \operatorname{Tg}($ myl7:BFP-CAAX);(myl7:nlsDsRed) hearts. E, I) The colors of wild-type dots refer to $t c f 21^{+/+}$(red) or $w t 1 a^{+/+}$(orange) siblings, or NTR ${ }^{+}$ MTZ-treated (grey) siblings. E, I) Mean \pm SD (E) or median and quartiles (I); $P$ values from 
Boezio et al., 2021

$t$ - or Mann-Whitney tests (following normality test), compared with WT/control siblings of each genotype/treatment. A, atrium; V, ventricle.

Figure S4: An intact epicardium is required to promote ventricular growth and prevent cardiomyocyte extrusion

A-C) Confocal images of $96 \mathrm{hpf} \operatorname{TgBAC}(t c f 21: N L S-E G F P) ; \operatorname{Tg}(m y l 7: B F P-C A A X) t c f 21^{+/+}$ (A) and $t c f 21^{-/}(\mathrm{B}, \mathrm{C})$ hearts, with different degrees of epicardial coverage (green). D, F) Pearson correlation between ventricular volume (D) and extruding CMs (F) (X axis), and the number of ventricular $t c f 21^{+}$cells (Y axis) in $96 t c f 21^{-/-}$larvae. E, E') Single confocal plane of a $76 \mathrm{hpf} \operatorname{TgBAC}(\operatorname{tcf} 21: N L S-E G F P) ; \operatorname{Tg}(m y l 7: m C h e r r y-C A A X) \operatorname{tcf} 21^{-/-}$ventricle, exhibiting an extruding CM covered by a $t c f 21^{+}$epicardial cell (nucleus, green; cell body highlighted with dashed line).

Figure S5: $f g f 24$ and vegfaa expression is enriched in epicardial cells and downregulated in $\operatorname{tcf} 21^{-/-}$hearts

A) $f g f 24$ and vegfaa mRNA levels obtained by RT-qPCR on extracted $96 \mathrm{hpf} t c f 21^{+/+}$and tcf $21^{-/-}$hearts; means $\pm \mathrm{SD} ; P$ values from Mann Whitney tests; $\mathrm{Ct}$ values are listed in

Supplementary Table 1. B, B') In situ hybridization showing $f g f 24$ expression in 76 hpf hearts $(\mathrm{n}=11 / 11)$. MF20 immunostaining (green) labels the myocardium (dashed lines).

Arrowheads, epicardial cells outside of the myocardial wall (enlarged in the box). C-D'”) Confocal images of 76 (C) and 96 (D) hpf TgBAC(vegfaa:EGFP); $\operatorname{Tg}(m y l 7: B F P-C A A X)$; $T g B A C(t c f 21: m C h e r r y-N T R)$ ventricles. $T g B A C$ (vegfaa:EGFP) expression is restricted to the epicardium (here seen on the ventricle and OFT) as well as OFT SMCs (white arrowheads). A, atrium; V, ventricle; OFT, outflow tract.

Supplementary Table 1: Ct values of genes by RT-qPCR and primers.

Supplementary Table 2: List of the top differentially expressed genes ( $>1$ or $<-1 \log 2 \mathrm{FC}$, baseMean > 50) from RNA-seq dataset of $96 \mathrm{hpf} \mathrm{CMs} \mathrm{sorted} \mathrm{from} t c f 21^{+/+}$and $t c f 21^{-/}$ larval hearts.

Supplementary Table 3: List of the top differentially expressed genes $(>1$ or $<-1 \log 2 \mathrm{FC}$, baseMean > 50) from RNA-seq dataset of $96 \mathrm{hpf}$ EpiCs sorted from $t c f 21^{+/+}$and $t c f 21^{-/-}$ larval hearts. 
Boezio et al., 2021

References

Acharya, A., Baek, S. T., Huang, G., Eskiocak, B., Goetsch, S., Sung, C. Y., Banfi, S., Sauer, M. F., Olsen, G. S., Duffield, J. S., et al. (2012). The bHLH transcription factor Tcf21 is required for lineage-specific EMT of cardiac fibroblast progenitors. Development 139, 2139-2149.

Auman, H. J., Coleman, H., Riley, H. E., Olale, F., Tsai, H. J. and Yelon, D. (2007). Functional modulation of cardiac form through regionally confined cell shape changes. PLOS Biol 5, e53.

Boezio, G. L., Bensimon-Brito, A., Piesker, J., Guenther, S., Helker, C. S. and Stainier, D. Y. (2020). Endothelial TGF-beta signaling instructs smooth muscle cell development in the cardiac outflow tract. Elife 9.

Brade, T., Kumar, S., Cunningham, T. J., Chatzi, C., Zhao, X., Cavallero, S., Li, P., Sucov, H. M., RuizLozano, P. and Duester, G. (2011). Retinoic acid stimulates myocardial expansion by induction of hepatic erythropoietin which activates epicardial Igf2. Development 138, 139148.

Bruton, F. A., Kaveh, A., Ross-Stewart, K. M., Matrone, G., Oremek, M. E. M., Solomonidis, E. G., Tucker, C. S., Mullins, J. J., Brittan, M., Taylor, J. M., et al. (2021). Macrophages stimulate epicardial VEGFaa expression to trigger cardiomyocyte proliferation in larval zebrafish heart regeneration. bioRxiv, 2021.2006.2015.448575.

Burg, L., Zhang, K., Bonawitz, T., Grajevskaja, V., Bellipanni, G., Waring, R. and Balciunas, D. (2016). Internal epitope tagging informed by relative lack of sequence conservation. Sci Rep 6, 36986.

Cao, J., Navis, A., Cox, B. D., Dickson, A. L., Gemberling, M., Karra, R., Bagnat, M. and Poss, K. D. (2016). Single epicardial cell transcriptome sequencing identifies Caveolin 1 as an essential factor in zebrafish heart regeneration. Development 143, 232-243.

Cao, J. and Poss, K. D. (2018). The epicardium as a hub for heart regeneration. Nat Rev Cardiol 15, 631-647.

Choi, W. Y., Gemberling, M., Wang, J., Holdway, J. E., Shen, M. C., Karlstrom, R. O. and Poss, K. D. (2013). In vivo monitoring of cardiomyocyte proliferation to identify chemical modifiers of heart regeneration. Development 140, 660-666.

Curado, S., Anderson, R. M., Jungblut, B., Mumm, J., Schroeter, E. and Stainier, D. Y. (2007). Conditional targeted cell ablation in zebrafish: a new tool for regeneration studies. Dev Dyn 236, 1025-1035.

Curado, S., Stainier, D. Y. and Anderson, R. M. (2008). Nitroreductase-mediated cell/tissue ablation in zebrafish: a spatially and temporally controlled ablation method with applications in developmental and regeneration studies. Nat Protoc 3, 948-954.

D'Amico, L., Scott, I. C., Jungblut, B. and Stainier, D. Y. (2007). A mutation in zebrafish hmgcr1b reveals a role for isoprenoids in vertebrate heart-tube formation. Curr Biol 17, 252-259.

Davis, M. P., van Dongen, S., Abreu-Goodger, C., Bartonicek, N. and Enright, A. J. (2013). Kraken: a set of tools for quality control and analysis of high-throughput sequence data. Methods 63, 41-49.

de la Cova, C., Townley, R., Regot, S. and Greenwald, I. (2017). A Real-Time Biosensor for ERK Activity Reveals Signaling Dynamics during C. elegans Cell Fate Specification. Dev Cell 42, $542-$ 553 e544.

De Simone, A., Evanitsky, M. N., Hayden, L., Cox, B. D., Wang, J., Tornini, V. A., Ou, J., Chao, A., Poss, K. D. and Di Talia, S. (2021). Control of osteoblast regeneration by a train of Erk activity waves. Nature 590, 129-133.

Dobin, A., Davis, C. A., Schlesinger, F., Drenkow, J., Zaleski, C., Jha, S., Batut, P., Chaisson, M. and Gingeras, T. R. (2013). STAR: ultrafast universal RNA-seq aligner. Bioinformatics 29, 15-21.

Eid, H., Larson, D. M., Springhorn, J. P., Attawia, M. A., Nayak, R. C., Smith, T. W. and Kelly, R. A. (1992). Role of epicardial mesothelial cells in the modification of phenotype and function of adult rat ventricular myocytes in primary coculture. Circ Res 71, 40-50. 
Boezio et al., 2021

El-Brolosy, M. A., Kontarakis, Z., Rossi, A., Kuenne, C., Gunther, S., Fukuda, N., Kikhi, K., Boezio, G. L. M., Takacs, C. M., Lai, S. L., et al. (2019). Genetic compensation triggered by mutant mRNA degradation. Nature 568, 193-197.

Gagnon, J. A., Valen, E., Thyme, S. B., Huang, P., Akhmetova, L., Pauli, A., Montague, T. G., Zimmerman, S., Richter, C. and Schier, A. F. (2014). Efficient mutagenesis by Cas9 proteinmediated oligonucleotide insertion and large-scale assessment of single-guide RNAs. PLOS One 9, e98186.

Guerra, A., Germano, R. F., Stone, O., Arnaout, R., Guenther, S., Ahuja, S., Uribe, V., Vanhollebeke, B., Stainier, D. Y. and Reischauer, S. (2018). Distinct myocardial lineages break atrial symmetry during cardiogenesis in zebrafish. Elife 7.

Jimenez-Amilburu, V., Rasouli, S. J., Staudt, D. W., Nakajima, H., Chiba, A., Mochizuki, N. and Stainier, D. Y. R. (2016). In Vivo Visualization of Cardiomyocyte Apicobasal Polarity Reveals Epithelial to Mesenchymal-like Transition during Cardiac Trabeculation. Cell Rep 17, 26872699.

Jorgensen, P. and Tyers, M. (2004). How cells coordinate growth and division. Curr Biol 14, R10141027.

Karra, R., Foglia, M. J., Choi, W. Y., Belliveau, C., DeBenedittis, P. and Poss, K. D. (2018). Vegfaa instructs cardiac muscle hyperplasia in adult zebrafish. Proc Natl Acad Sci U S A 115, 88058810.

Kastner, P., Grondona, J. M., Mark, M., Gansmuller, A., LeMeur, M., Decimo, D., Vonesch, J. L., Dolle, P. and Chambon, P. (1994). Genetic analysis of RXR alpha developmental function: convergence of RXR and RAR signaling pathways in heart and eye morphogenesis. Cell 78, 987-1003.

Lavine, K. J., Yu, K., White, A. C., Zhang, X., Smith, C., Partanen, J. and Ornitz, D. M. (2005). Endocardial and epicardial derived FGF signals regulate myocardial proliferation and differentiation in vivo. Dev Cell 8, 85-95.

Li, P., Cavallero, S., Gu, Y., Chen, T. H., Hughes, J., Hassan, A. B., Bruning, J. C., Pashmforoush, M. and Sucov, H. M. (2011). IGF signaling directs ventricular cardiomyocyte proliferation during embryonic heart development. Development 138, 1795-1805.

Li, Y., Urban, A., Midura, D., Simon, H. G. and Wang, Q. T. (2017). Proteomic characterization of epicardial-myocardial signaling reveals novel regulatory networks including a role for NFkappaB in epicardial EMT. PLoS One 12, e0174563.

Liang, D., Chang, J. R., Chin, A. J., Smith, A., Kelly, C., Weinberg, E. S. and Ge, R. (2001). The role of vascular endothelial growth factor (VEGF) in vasculogenesis, angiogenesis, and hematopoiesis in zebrafish development. Mech Dev 108, 29-43.

Liao, Y., Smyth, G. K. and Shi, W. (2014). featureCounts: an efficient general purpose program for assigning sequence reads to genomic features. Bioinformatics 30, 923-930.

Liu, J. and Stainier, D. Y. (2010). Tbx5 and Bmp signaling are essential for proepicardium specification in zebrafish. Circ Res 106, 1818-1828.

Love, M. I., Huber, W. and Anders, S. (2014). Moderated estimation of fold change and dispersion for RNA-seq data with DESeq2. Genome Biol 15, 550.

Mahtab, E. A., Vicente-Steijn, R., Hahurij, N. D., Jongbloed, M. R., Wisse, L. J., DeRuiter, M. C., Uhrin, P., Zaujec, J., Binder, B. R., Schalij, M. J., et al. (2009). Podoplanin deficient mice show a RhoA-related hypoplasia of the sinus venosus myocardium including the sinoatrial node. Dev Dyn 238, 183-193.

Manner, J. (1993). Experimental study on the formation of the epicardium in chick embryos. Anat Embryol (Berl) 187, 281-289.

Manner, J., Schlueter, J. and Brand, T. (2005). Experimental analyses of the function of the proepicardium using a new microsurgical procedure to induce loss-of-proepicardial-function in chick embryos. Dev Dyn 233, 1454-1463.

Marin-Juez, R., Marass, M., Gauvrit, S., Rossi, A., Lai, S. L., Materna, S. C., Black, B. L. and Stainier, D. Y. (2016). Fast revascularization of the injured area is essential to support zebrafish heart regeneration. Proc Natl Acad Sci U S A 113, 11237-11242. 
Boezio et al., 2021

Masters, M. and Riley, P. R. (2014). The epicardium signals the way towards heart regeneration. Stem Cell Res 13, 683-692.

Matsuoka, R. L., Marass, M., Avdesh, A., Helker, C. S., Maischein, H. M., Grosse, A. S., Kaur, H., Lawson, N. D., Herzog, W. and Stainier, D. Y. (2016). Radial glia regulate vascular patterning around the developing spinal cord. Elife $\mathbf{5}$.

Mayr, V., Sturtzel, C., Stadler, M., Grissenberger, S. and Distel, M. (2018). Fast Dynamic in vivo Monitoring of Erk Activity at Single Cell Resolution in DREKA Zebrafish. Front Cell Dev Biol 6, 111.

Mok, G. F., Cardenas, R., Anderton, H., Campbell, K. H. and Sweetman, D. (2014). Interactions between FGF18 and retinoic acid regulate differentiation of chick embryo limb myoblasts. Dev Biol 396, 214-223.

Moore, A. W., Mclnnes, L., Kreidberg, J., Hastie, N. D. and Schedl, A. (1999). YAC complementation shows a requirement for $\mathrm{Wt} 1$ in the development of epicardium, adrenal gland and throughout nephrogenesis. Development 126, 1845-1857.

Nagelberg, D., Wang, J., Su, R., Torres-Vazquez, J., Targoff, K. L., Poss, K. D. and Knaut, H. (2015). Origin, Specification, and Plasticity of the Great Vessels of the Heart. Curr Bio/ 25, 2099-2110.

Nauroy, P., Hughes, S., Naba, A. and Ruggiero, F. (2018). The in-silico zebrafish matrisome: A new tool to study extracellular matrix gene and protein functions. Matrix Biol 65, 5-13.

Okuda, K. S., Keyser, M., Gurevich, D. B., Sturtzel, C., Patterson, S., Chen, H., Scott, M., Condon, N. D., Martin, P., Distel, M., et al. (2020). Live-imaging of endothelial Erk activity reveals dynamic and sequential signalling events during regenerative angiogenesis. bioRxiv, 2020.2008.2017.254912.

Olivey, H. E. and Svensson, E. C. (2010). Epicardial-myocardial signaling directing coronary vasculogenesis. Circ Res 106, 818-832.

Pennisi, D. J., Ballard, V. L. and Mikawa, T. (2003). Epicardium is required for the full rate of myocyte proliferation and levels of expression of myocyte mitogenic factors FGF2 and its receptor, FGFR-1, but not for transmural myocardial patterning in the embryonic chick heart. Dev Dyn 228, 161-172.

Peralta, M., Gonzalez-Rosa, J. M., Marques, I. J. and Mercader, N. (2014). The Epicardium in the Embryonic and Adult Zebrafish. J Dev Biol 2, 101-116.

Peralta, M., Steed, E., Harlepp, S., Gonzalez-Rosa, J. M., Monduc, F., Ariza-Cosano, A., Cortes, A., Rayon, T., Gomez-Skarmeta, J. L., Zapata, A., et al. (2013). Heartbeat-driven pericardiac fluid forces contribute to epicardium morphogenesis. Curr Biol 23, 1726-1735.

Perez-Pomares, J. M., Phelps, A., Sedmerova, M. and Wessels, A. (2003). Epicardial-like cells on the distal arterial end of the cardiac outflow tract do not derive from the proepicardium but are derivatives of the cephalic pericardium. Dev Dyn 227, 56-68.

Pisharath, H., Rhee, J. M., Swanson, M. A., Leach, S. D. and Parsons, M. J. (2007). Targeted ablation of beta cells in the embryonic zebrafish pancreas using E. coli nitroreductase. Mech Dev 124, 218-229.

Priya, R., Allanki, S., Gentile, A., Mansingh, S., Uribe, V., Maischein, H. M. and Stainier, D. Y. R. (2020). Tension heterogeneity directs form and fate to pattern the myocardial wall. Nature 588, 130-134.

Quijada, P., Trembley, M. A. and Small, E. M. (2020). The Role of the Epicardium During Heart Development and Repair. Circ Res 126, 377-394.

Rasouli, S. J., El-Brolosy, M., Tsedeke, A. T., Bensimon-Brito, A., Ghanbari, P., Maischein, H. M., Kuenne, C. and Stainier, D. Y. (2018). The flow responsive transcription factor Klf2 is required for myocardial wall integrity by modulating Fgf signaling. Elife $\mathbf{7}$.

Rodgers, L. S., Lalani, S., Runyan, R. B. and Camenisch, T. D. (2008). Differential growth and multicellular villi direct proepicardial translocation to the developing mouse heart. Dev Dyn 237, 145-152.

Rossi, A., Gauvrit, S., Marass, M., Pan, L., Moens, C. B. and Stainier, D. Y. R. (2016). Regulation of Vegf signaling by natural and synthetic ligands. Blood 128, 2359-2366.

Serluca, F. C. (2008). Development of the proepicardial organ in the zebrafish. Dev Biol 315, 18-27. 
Boezio et al., 2021

Smith, C. L., Baek, S. T., Sung, C. Y. and Tallquist, M. D. (2011). Epicardial-derived cell epithelial-tomesenchymal transition and fate specification require PDGF receptor signaling. Circ Res 108, e15-26.

Smits, A. M., Dronkers, E. and Goumans, M. J. (2018). The epicardium as a source of multipotent adult cardiac progenitor cells: Their origin, role and fate. Pharmacol Res 127, 129-140.

Son, S., Kang, J. H., Oh, S., Kirschner, M. W., Mitchison, T. J. and Manalis, S. (2015). Resonant microchannel volume and mass measurements show that suspended cells swell during mitosis. J Cell Biol 211, 757-763.

Stuckmann, I., Evans, S. and Lassar, A. B. (2003). Erythropoietin and retinoic acid, secreted from the epicardium, are required for cardiac myocyte proliferation. Dev Biol 255, 334-349.

Sugiyama, M., Sakaue-Sawano, A., limura, T., Fukami, K., Kitaguchi, T., Kawakami, K., Okamoto, H., Higashijima, S. and Miyawaki, A. (2009). Illuminating cell-cycle progression in the developing zebrafish embryo. Proc Natl Acad Sci U S A 106, 20812-20817.

Takahashi, M., Yamagishi, T., Narematsu, M., Kamimura, T., Kai, M. and Nakajima, Y. (2014). Epicardium is required for sarcomeric maturation and cardiomyocyte growth in the ventricular compact layer mediated by transforming growth factor beta and fibroblast growth factor before the onset of coronary circulation. Congenit Anom (Kyoto) 54, 162-171.

Takeuchi, J. K., Lou, X., Alexander, J. M., Sugizaki, H., Delgado-Olguin, P., Holloway, A. K., Mori, A. D., Wylie, J. N., Munson, C., Zhu, Y., et al. (2011). Chromatin remodelling complex dosage modulates transcription factor function in heart development. Nat Commun 2, 187.

Thisse, C. and Thisse, B. (2008). High-resolution in situ hybridization to whole-mount zebrafish embryos. Nat Protoc 3, 59-69.

Uribe, V., Ramadass, R., Dogra, D., Rasouli, S. J., Gunawan, F., Nakajima, H., Chiba, A., Reischauer, S., Mochizuki, N. and Stainier, D. Y. R. (2018). In vivo analysis of cardiomyocyte proliferation during trabeculation. Development 145.

Varshney, G. K., Pei, W., LaFave, M. C., Idol, J., Xu, L., Gallardo, V., Carrington, B., Bishop, K., Jones, M., Li, M., et al. (2015). High-throughput gene targeting and phenotyping in zebrafish using CRISPR/Cas9. Genome Res 25, 1030-1042.

Vega-Hernandez, M., Kovacs, A., De Langhe, S. and Ornitz, D. M. (2011). FGF10/FGFR2b signaling is essential for cardiac fibroblast development and growth of the myocardium. Development 138, 3331-3340.

Wang, J., Cao, J., Dickson, A. L. and Poss, K. D. (2015). Epicardial regeneration is guided by cardiac outflow tract and Hedgehog signalling. Nature 522, 226-230.

Weinberger, M., Simoes, F. C., Patient, R., Sauka-Spengler, T. and Riley, P. R. (2020). Functional Heterogeneity within the Developing Zebrafish Epicardium. Dev Cell 52, 574-590 e576.

Weinberger, M., Simões, F. C., Sauka-Spengler, T. and Riley, P. R. (2021). Distinct epicardial gene regulatory programmes drive development and regeneration of the zebrafish heart. bioRxiv, 2021.2006.2029.450229.

Wu, B., Zhang, Z., Lui, W., Chen, X., Wang, Y., Chamberlain, A. A., Moreno-Rodriguez, R. A., Markwald, R. R., O'Rourke, B. P., Sharp, D. J., et al. (2012). Endocardial cells form the coronary arteries by angiogenesis through myocardial-endocardial VEGF signaling. Cell 151, 1083-1096.

Zhang, S., Cao, Z., Tian, H., Shen, G., Ma, Y., Xie, H., Liu, Y., Zhao, C., Deng, S., Yang, Y., et al. (2011). SKLB1002, a novel potent inhibitor of VEGF receptor 2 signaling, inhibits angiogenesis and tumor growth in vivo. Clin Cancer Res 17, 4439-4450.

Zlotek-Zlotkiewicz, E., Monnier, S., Cappello, G., Le Berre, M. and Piel, M. (2015). Optical volume and mass measurements show that mammalian cells swell during mitosis. $J$ Cell Biol 211, 765-774. 
bioRxiv preprint doi: https://doi.org/10.1101/2021.08.09.455639; this version posted August 10, 2021. The copyright holder for this preprint Fig. 1 (which was not certified by peer review) is the author/funder, who has granted bioRxiv a license to display the preprint in perpetuity. It is
made available under aCC-BY-NC-ND 4.0 International license.

A

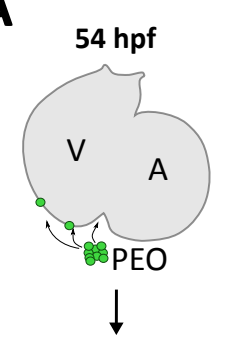

72-78 hpf

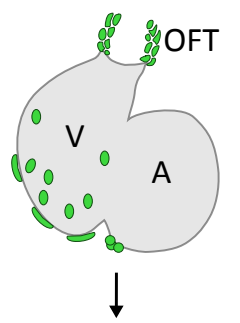

96-100 hpf

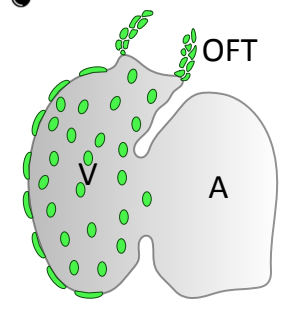

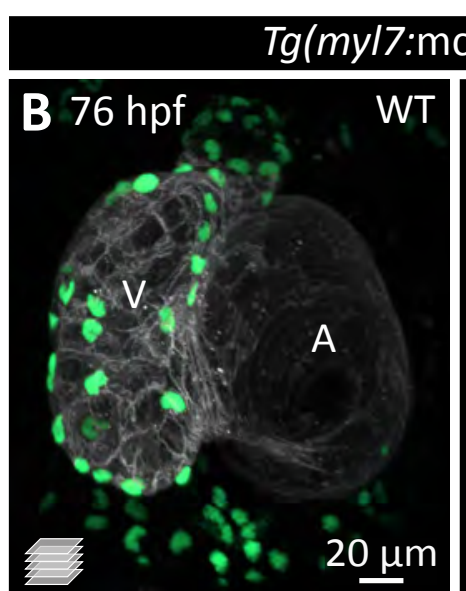

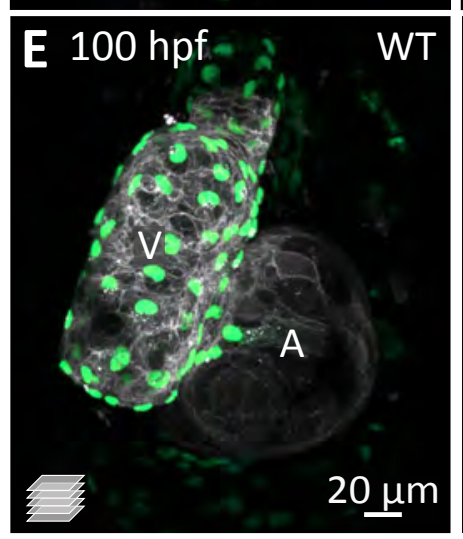

cherry-CAAX); $\operatorname{TgBAC}(\operatorname{tcf21:NLS-EGFP)}$
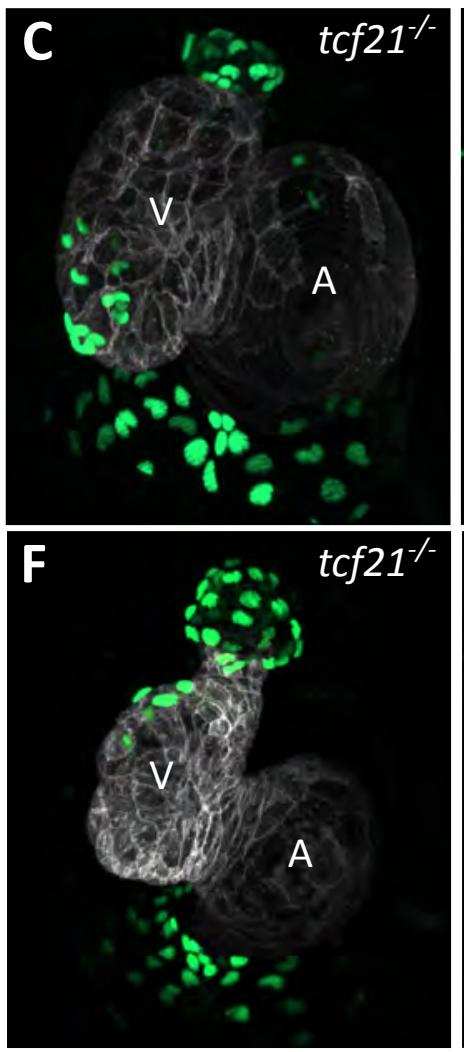

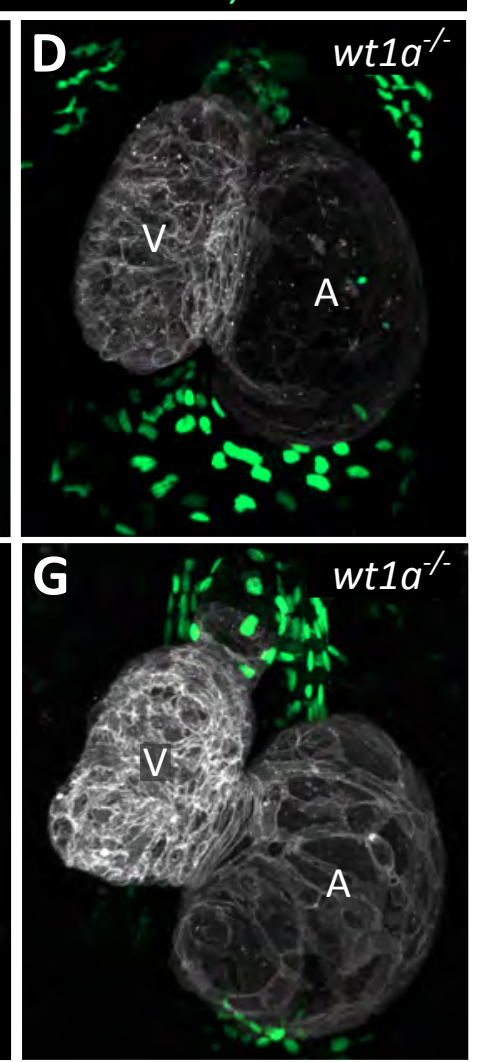

H $\quad 100 \mathrm{hpf}$

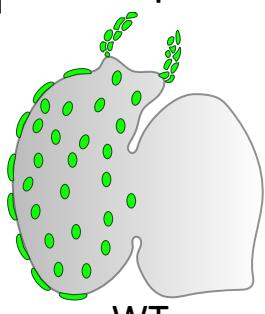

WT

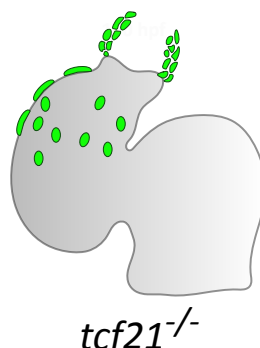

$\operatorname{tcf} 21^{-/}$

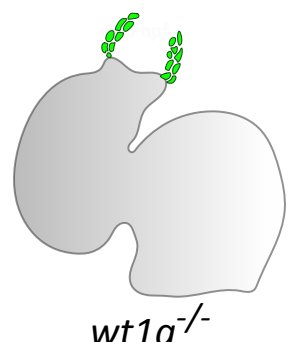

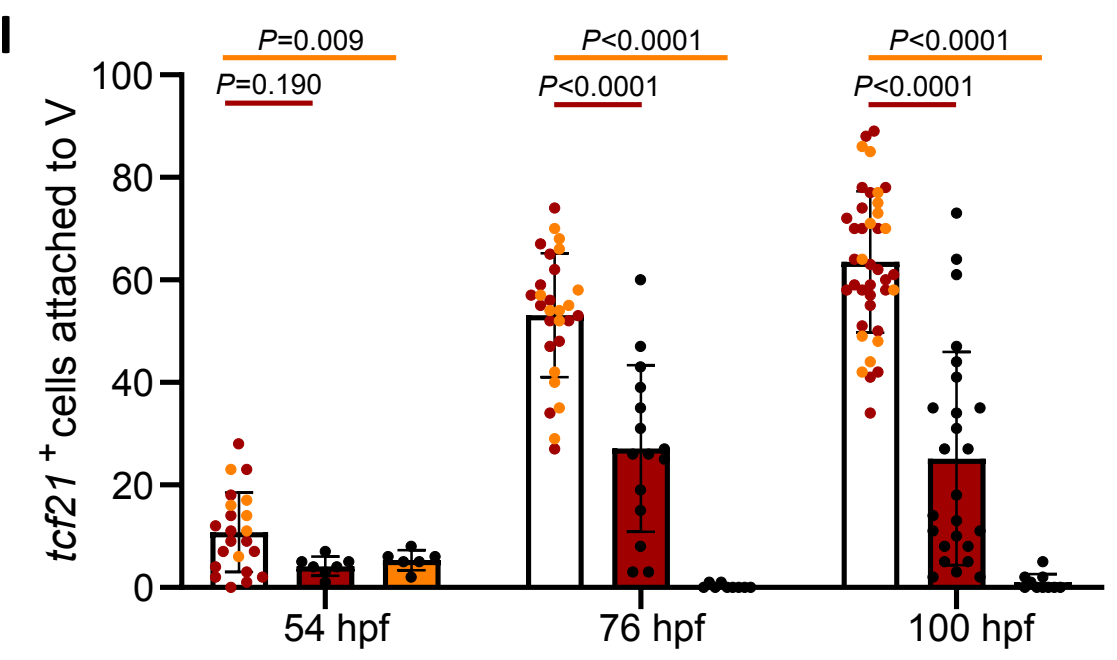

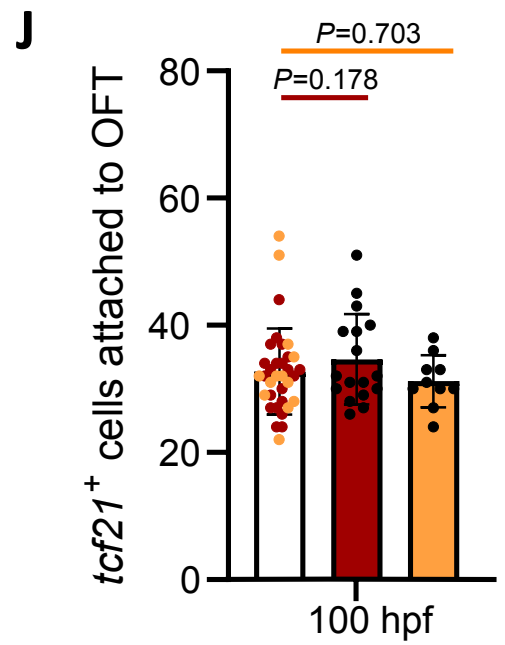

K
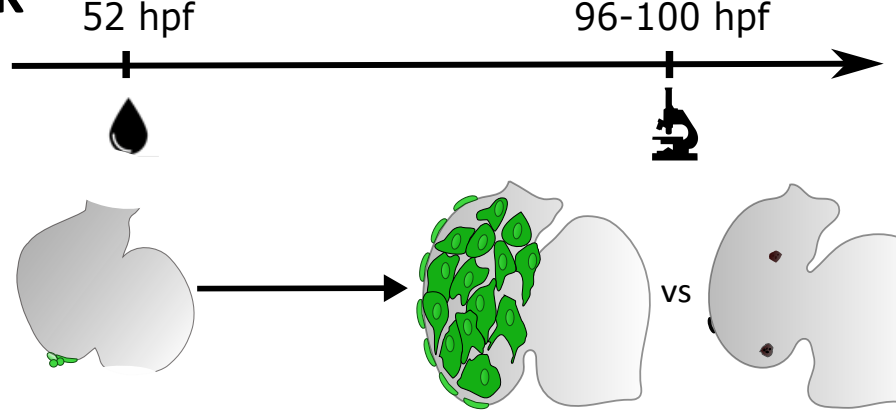

$\operatorname{Tg}(t c f 21: m$ Cherry-NTR)
DMSO

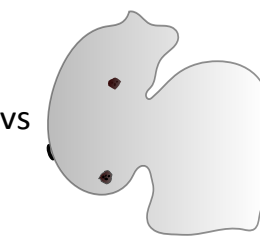

Metronidazole (MTZ)
Tg(myl7:EGFP-HRAS) TgBAC(tcf21:mCherry-NTR) 100 hpf
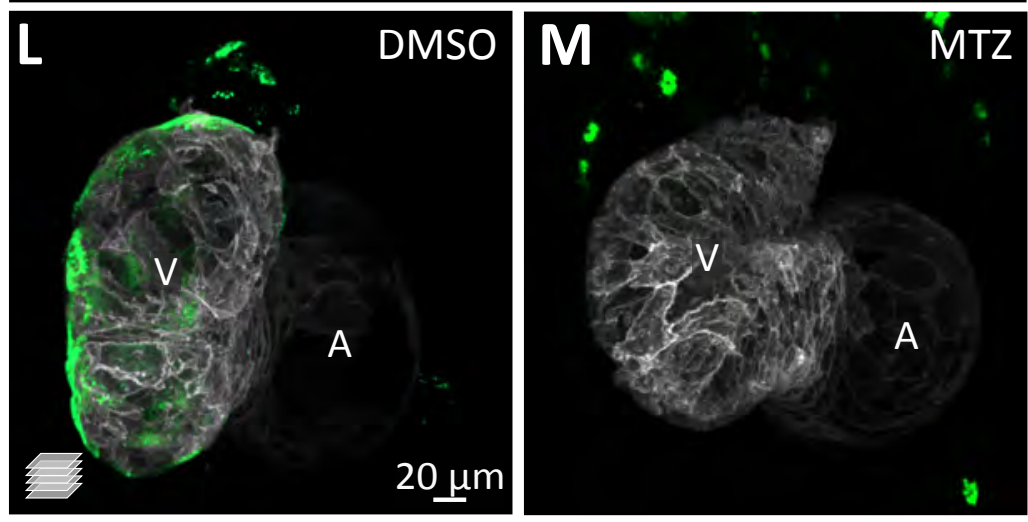
FIg. 2 (which was not certified by peer review) is the author/funder, who has granted bioRxiv a license to display the preprint in perpetuity. It is made available under aCC-BY-NC-ND 4.0 International license.
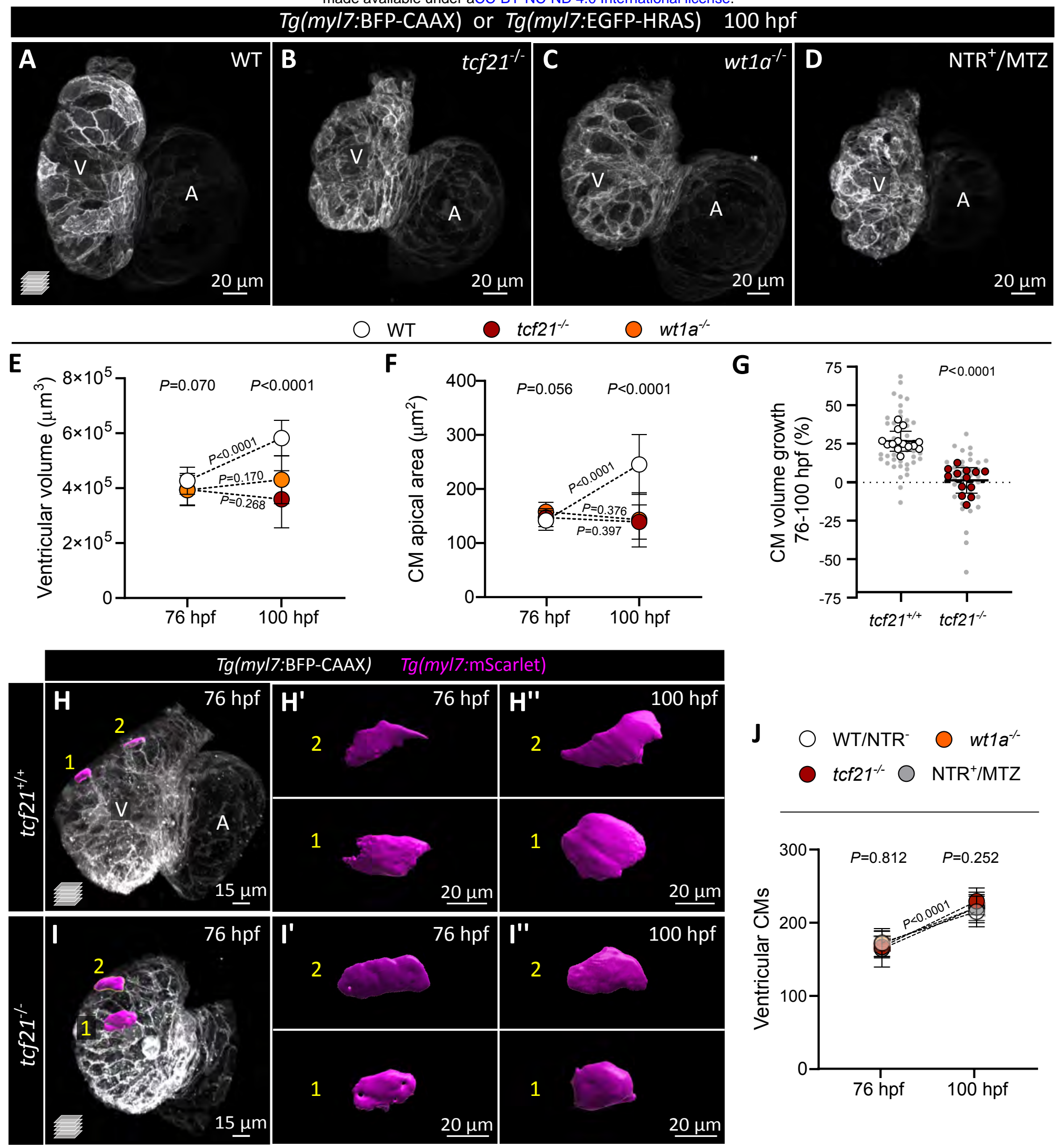

\section{M}

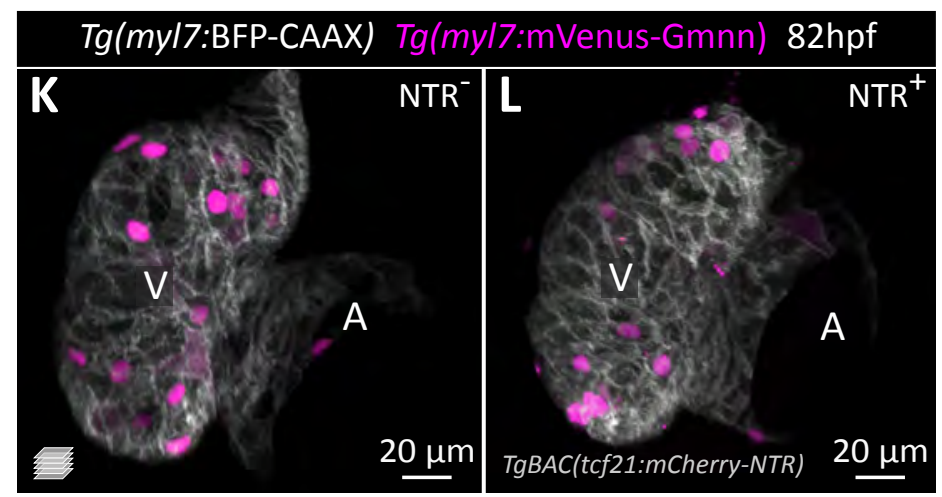

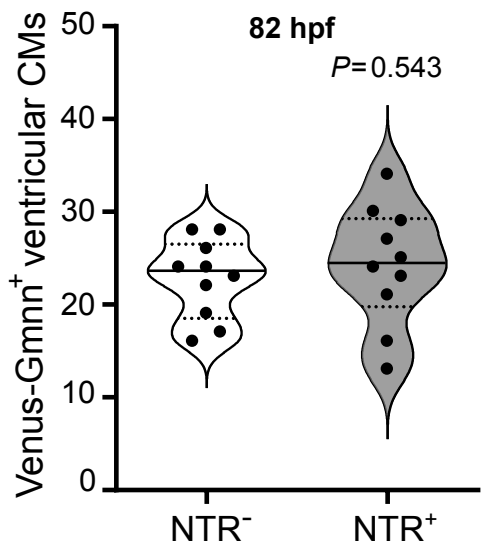

$\mathbf{N}$

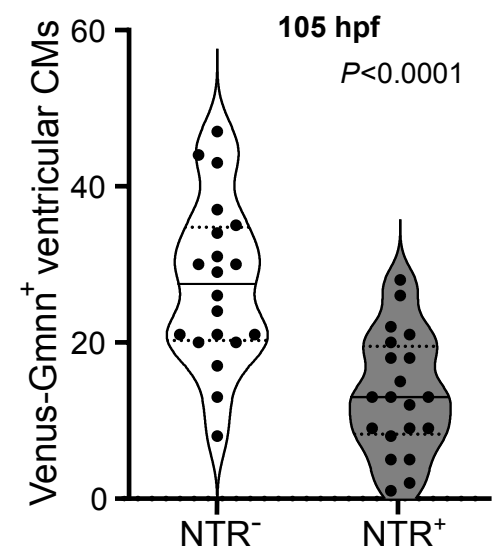


Ei Riviv preprint doi: https://doi.org/10.1101/2021.08.09.455639; this version posted August 10, 2021. The copyright holder for this preprint Fig. 3vhich was not certified by peer review) is the author/funder, who has granted bioRxiv a license to display the preprint in perpetuity. It is

A

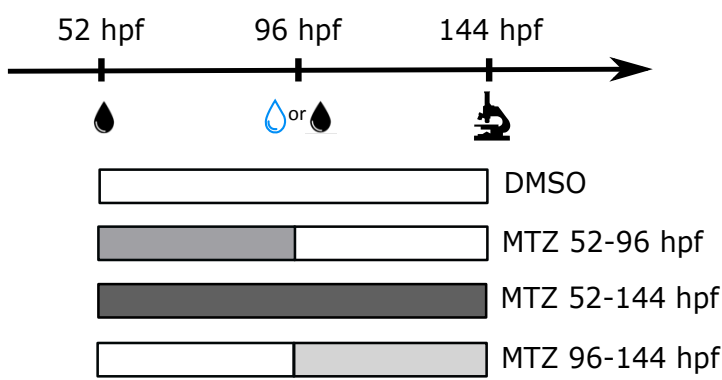

D

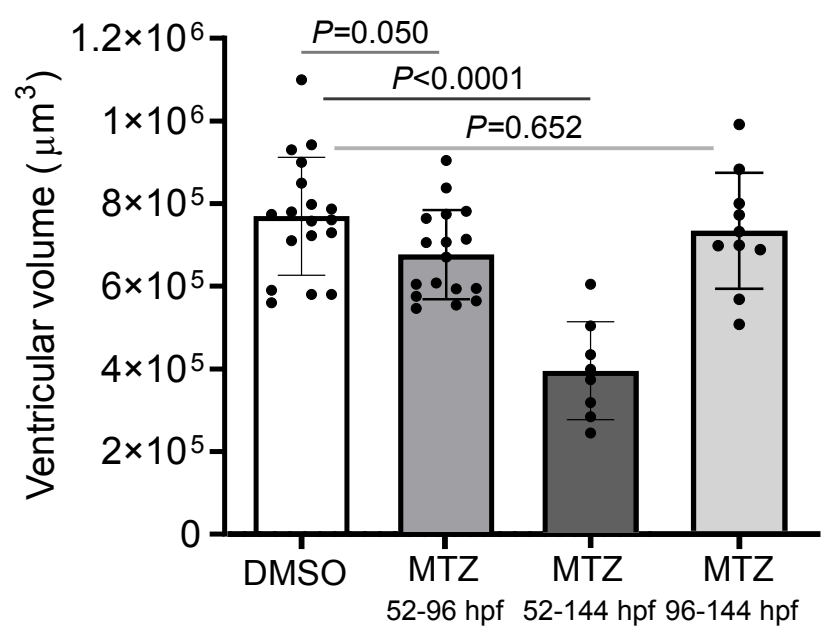

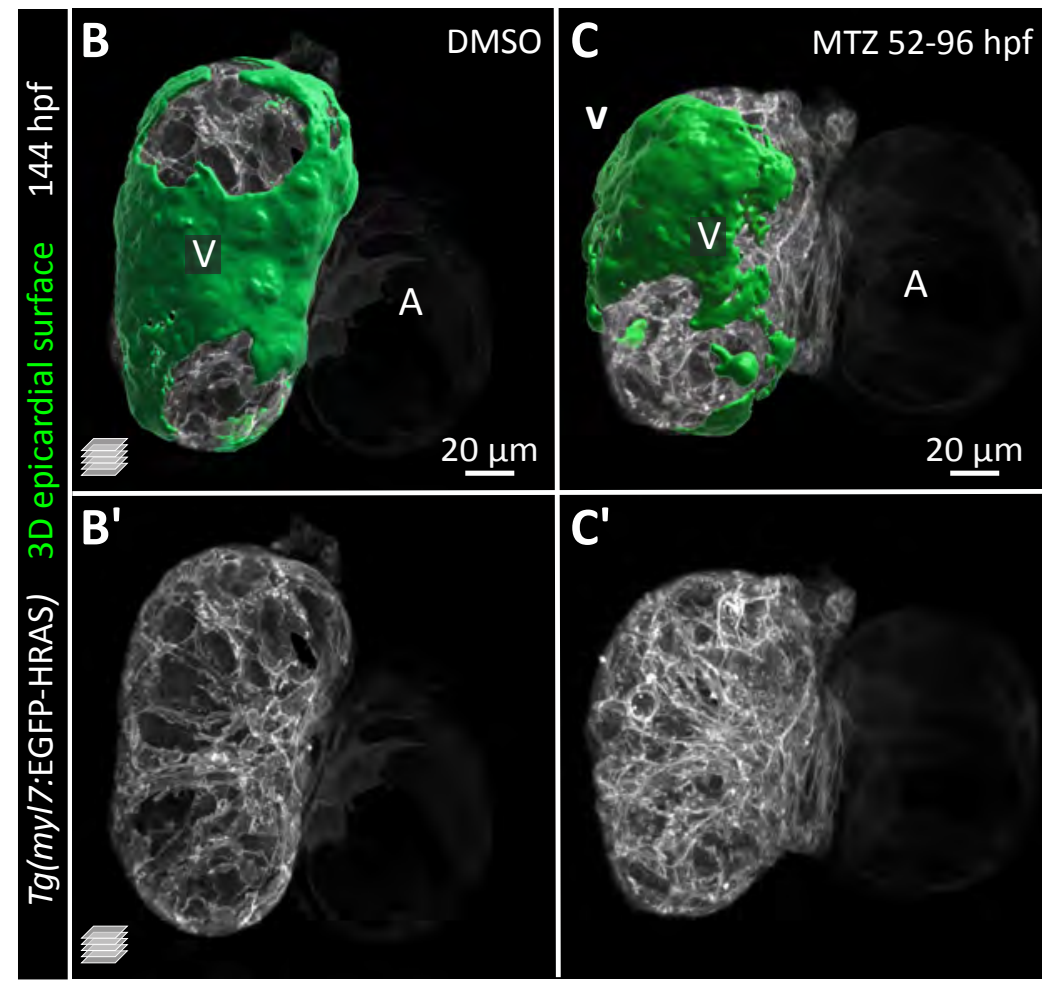

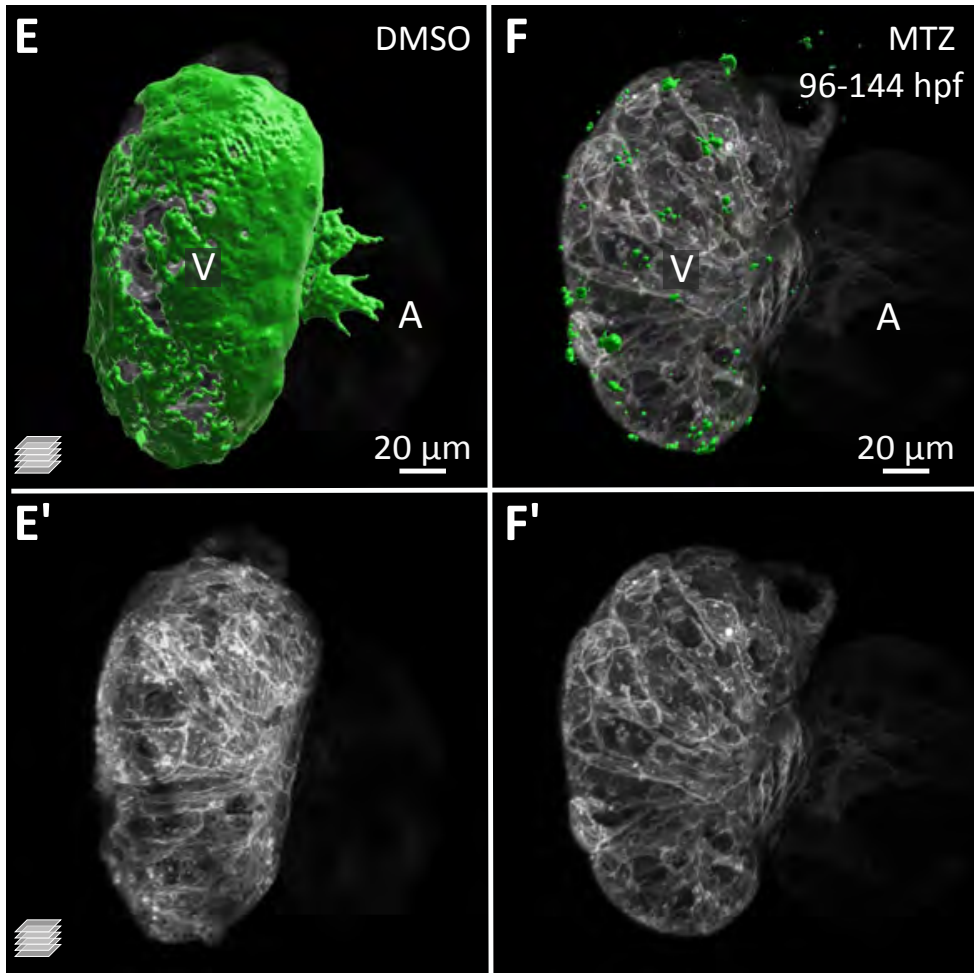


bioRxiv preprint doi: https://doi.org/10.1101/2021.08.09.455639; this version posted August 10, 2021. The copyright holder for this preprint Fig. 4 (which was not certified by peer review) is the author/funder, who has granted bioRxiv a license to display the preprint in perpetuity. It is
made available under aCC-BY-NC-ND 4.0 International license.

A

WT

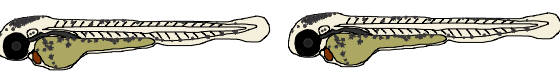

Tg(myl7:mCherry-CAAX)

$\operatorname{Tg}$ (tcf21:NLS-EGFP)
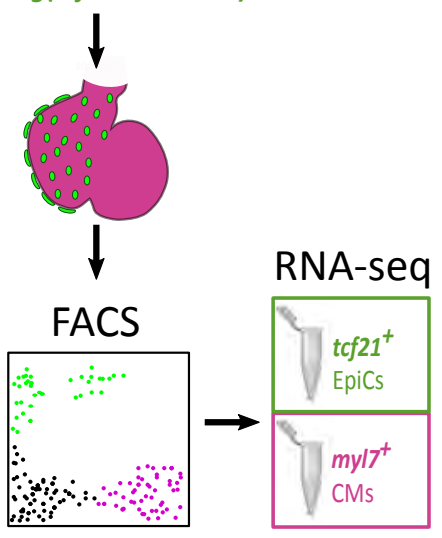

B

\section{Epi-enriched secreted factor genes}
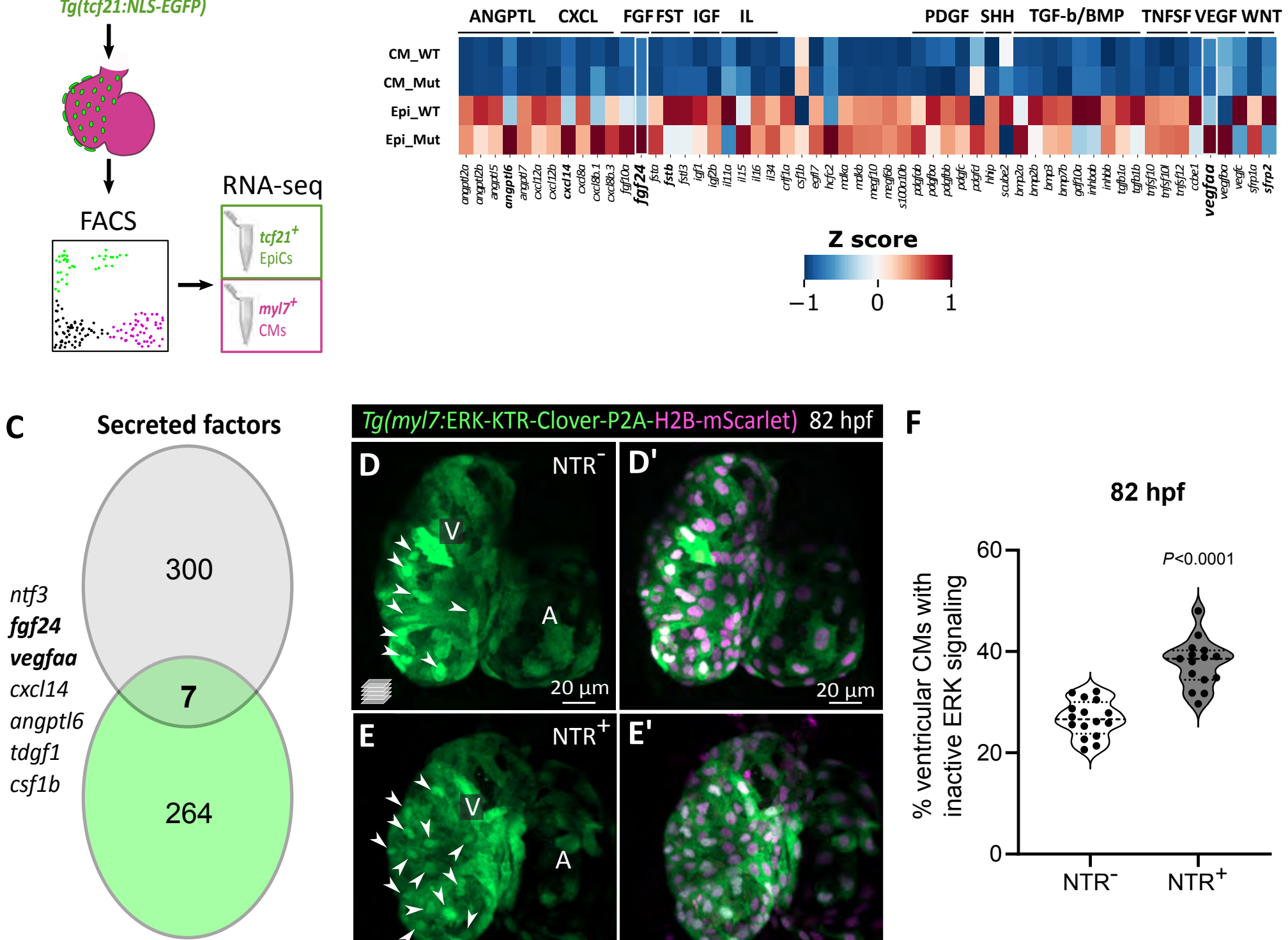

Mut EpiCs down

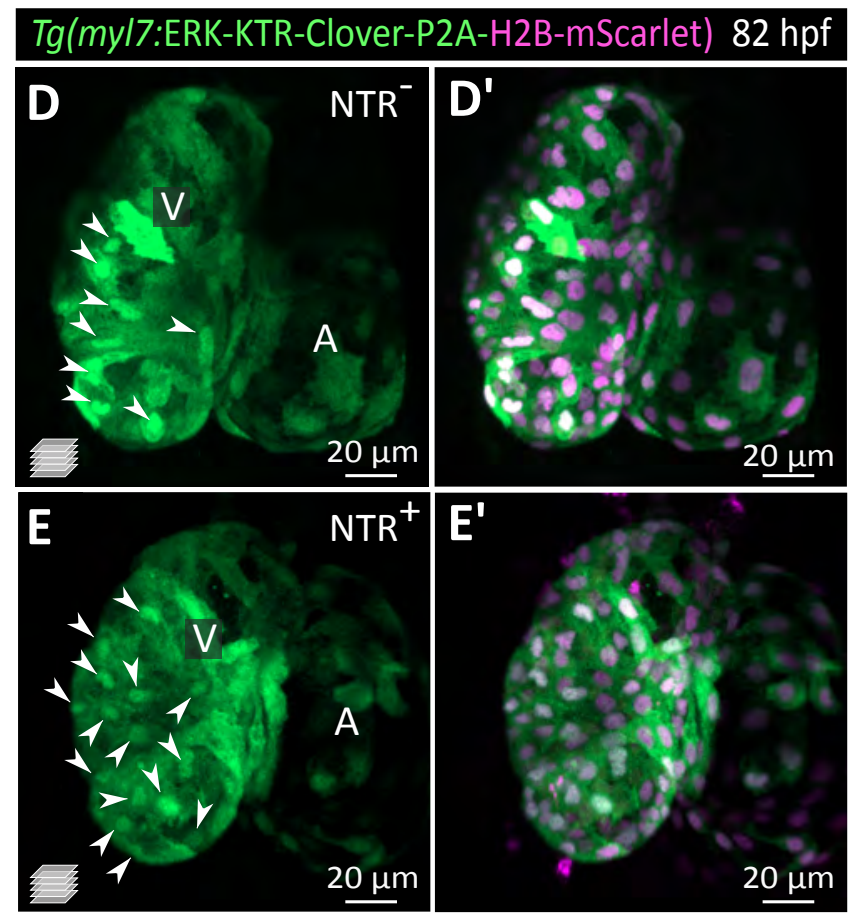

$\mathbf{F}$

82 hpf
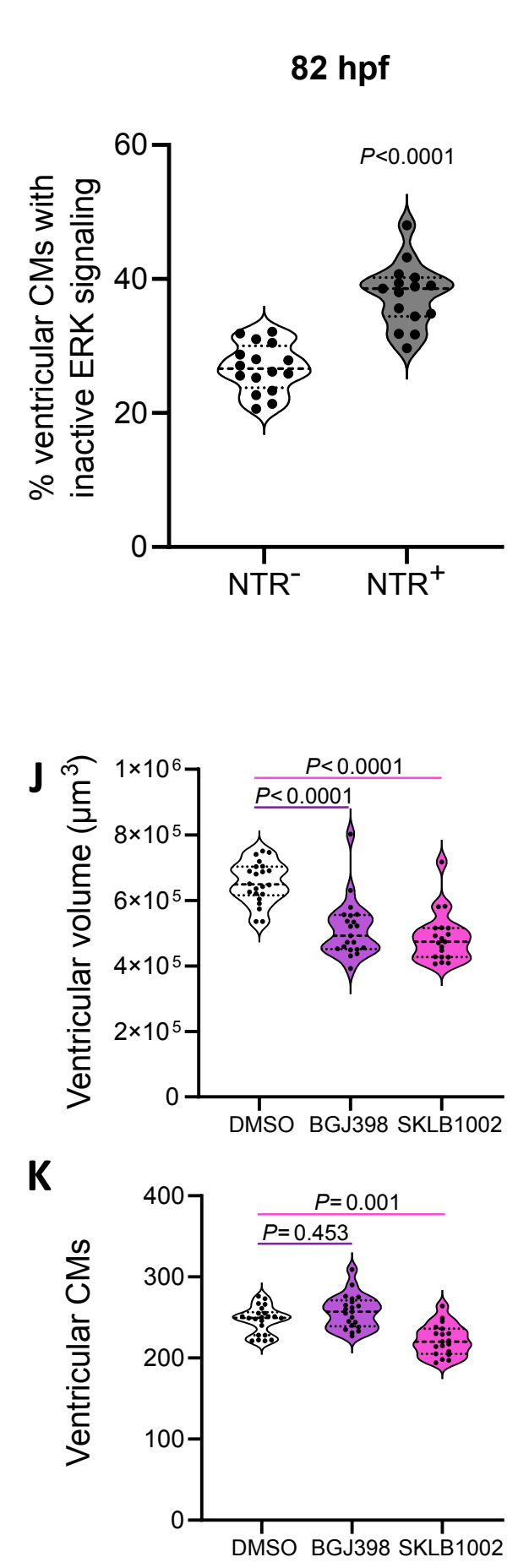

K

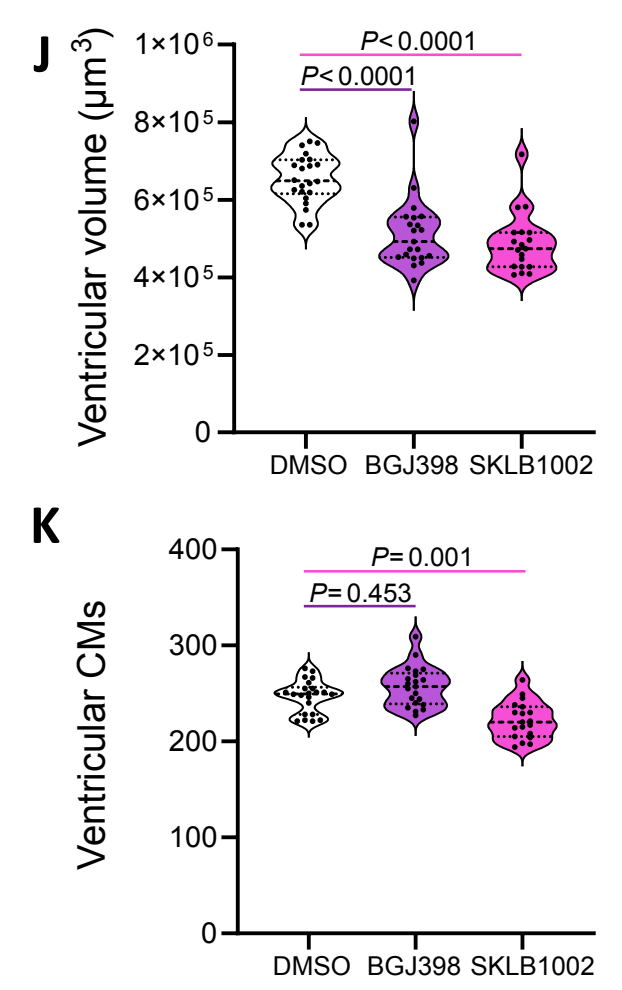

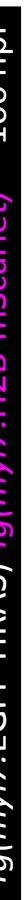
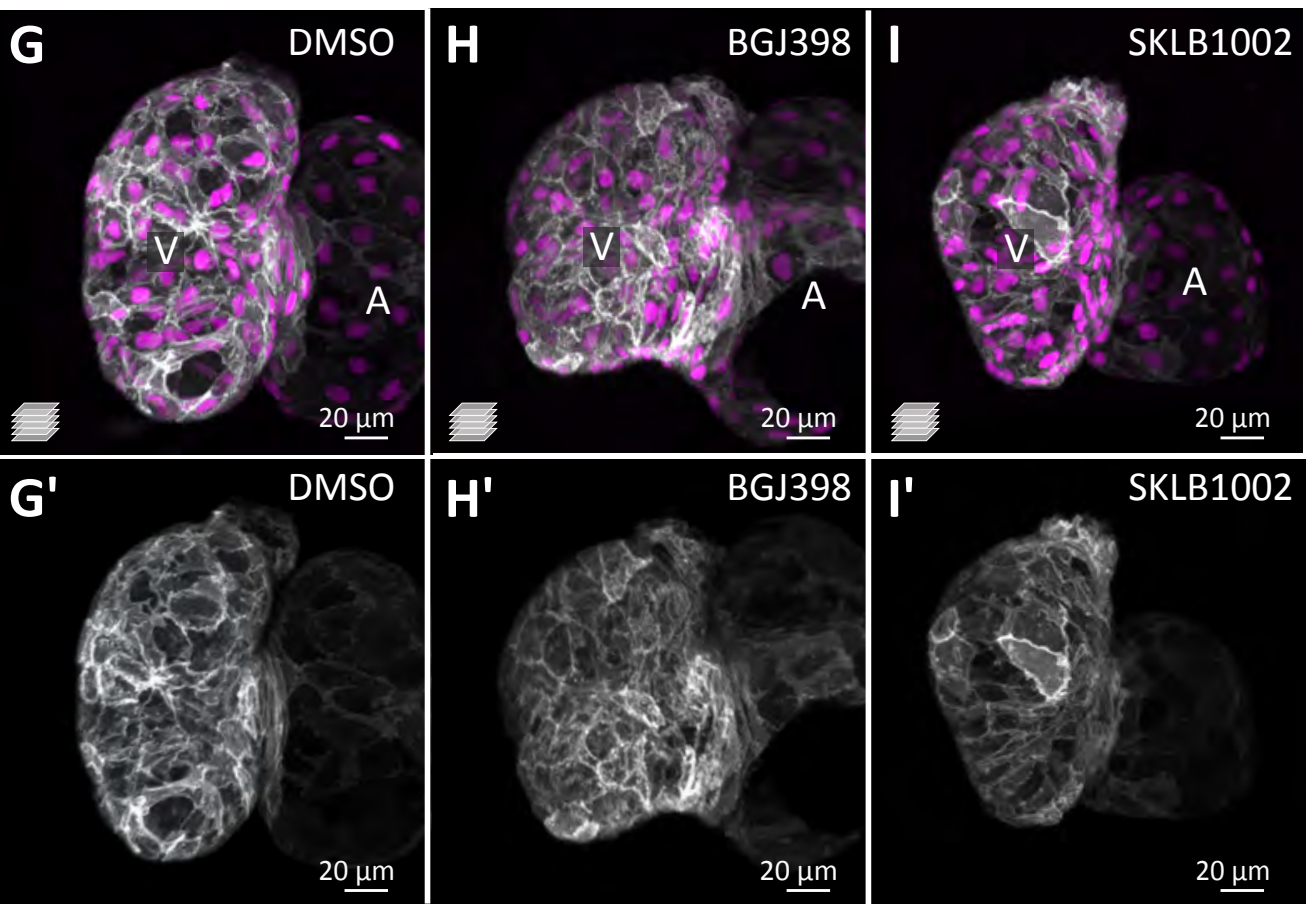
bioRxiv preprint doi: $h$ ttps://doi. org/10 1101/2021.08 09.455639: this version posted August 10 2021. The copyright holder for this preprint Fig. S1 hich was not certified by peer review) is the author/funder, who has granted bioRxiv a license to display the preprint in perpetuity. It is made available under aCC-BY-NC-ND 4.0 International license.

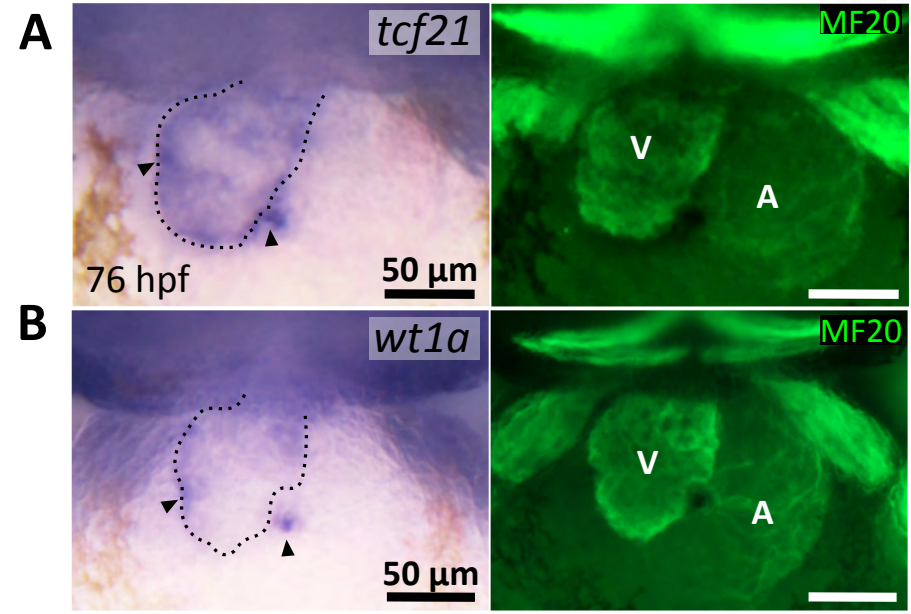

C ${ }_{\mathrm{Tcf}} 21^{\mathrm{WT}}$

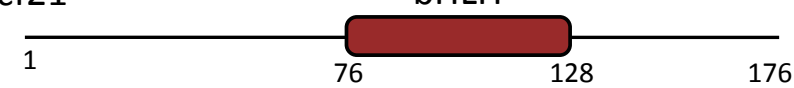

$\operatorname{Tcf} 21^{\text {bns } 427}$
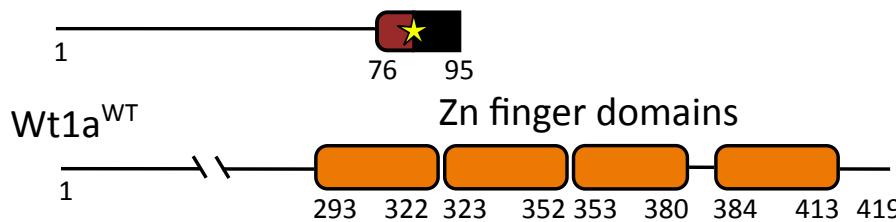

D
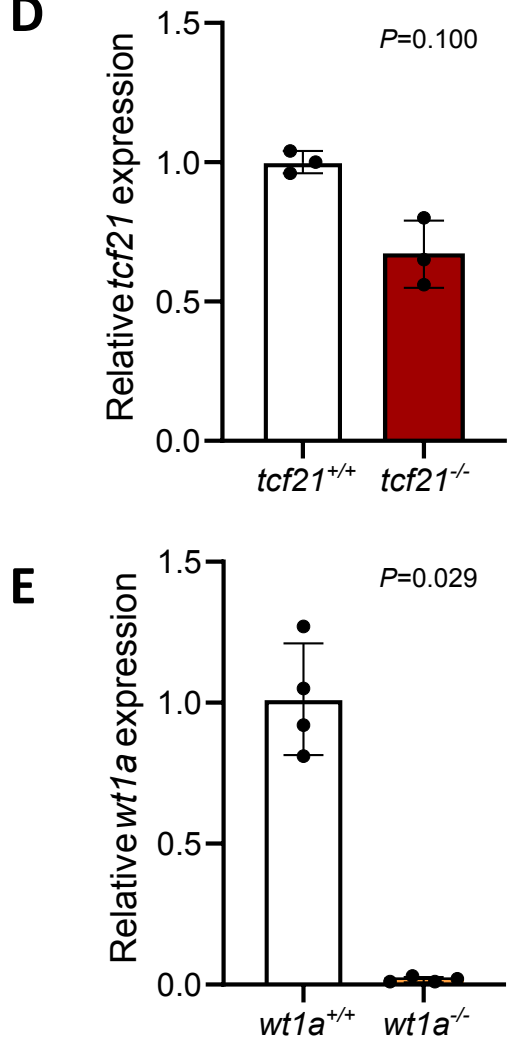
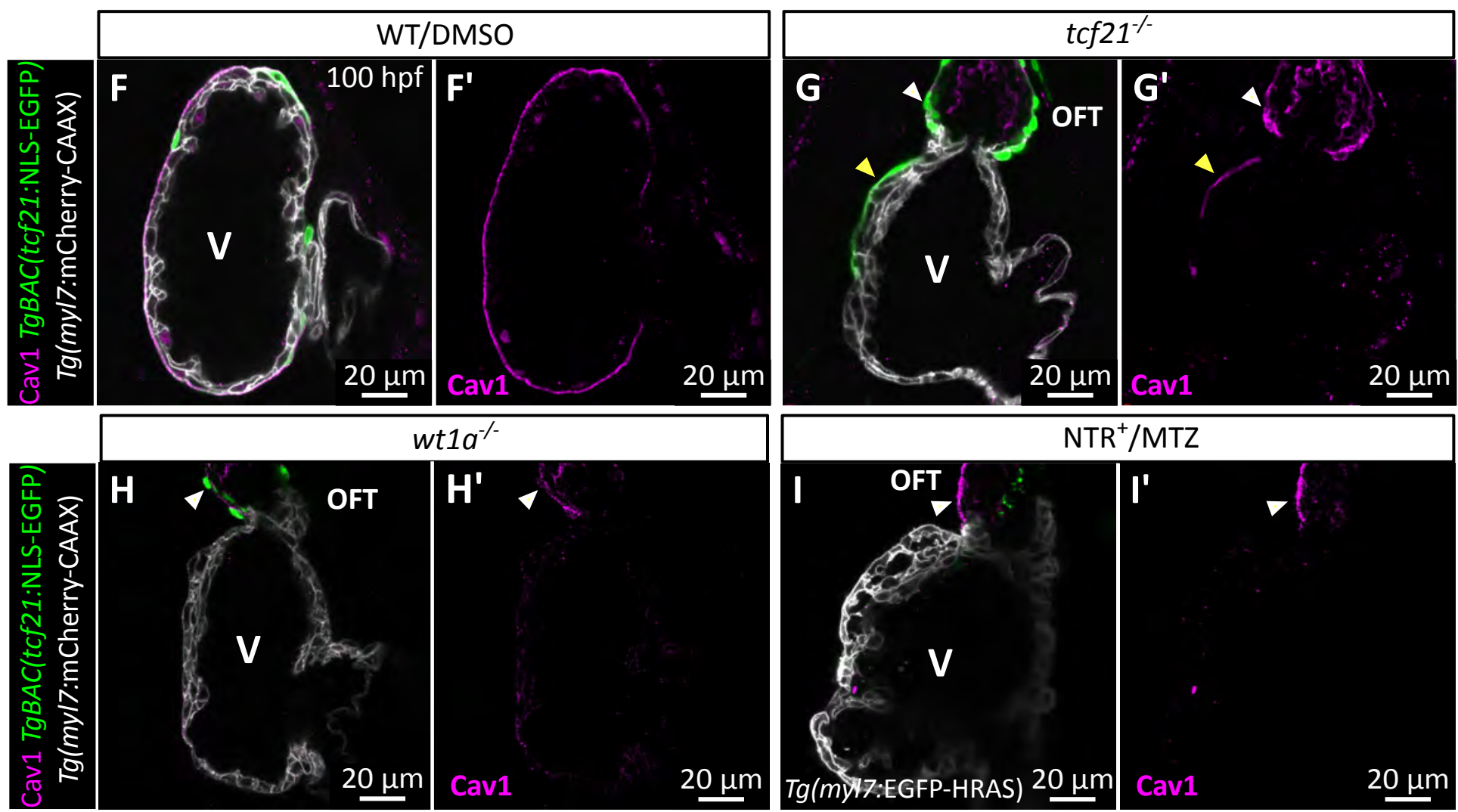

$\mathrm{R}^{+} / \mathrm{MTZ}$

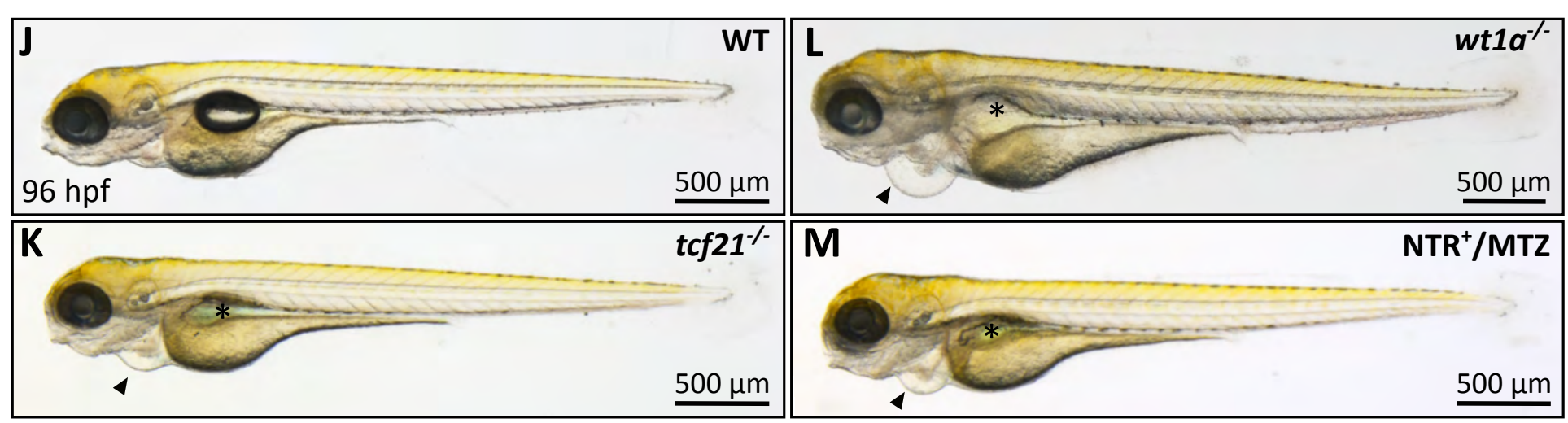


Fig. S2 made available under aCC-BY-NC-ND 4.0 International license.
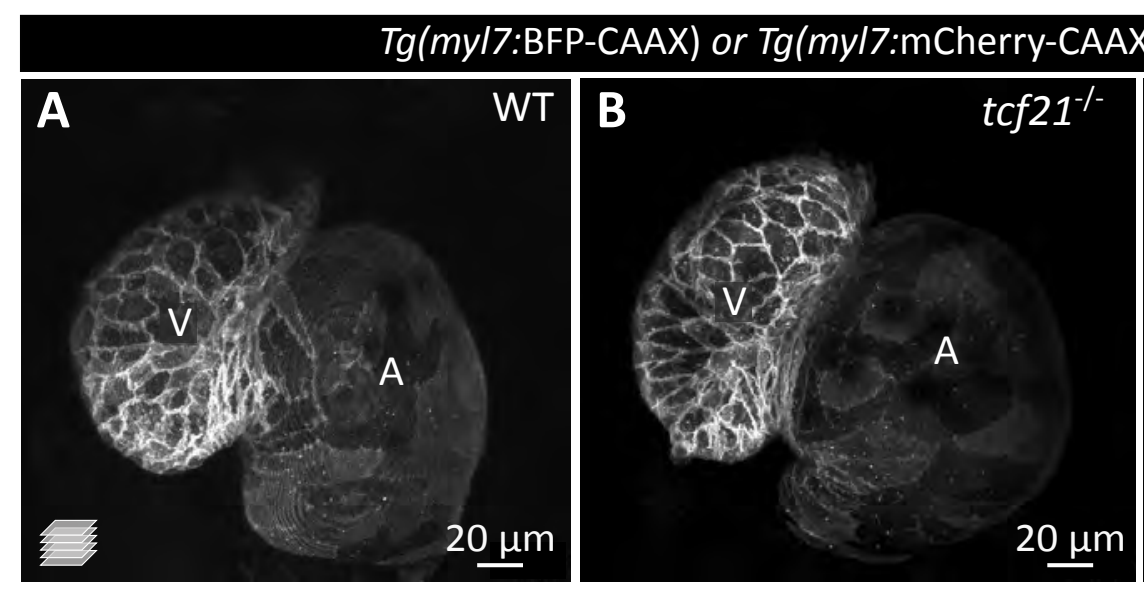

\section{$76 \mathrm{hpf}$}
WT/NTR'
tcf2 $1^{-1}$
wt1 $1 a^{-1-}$

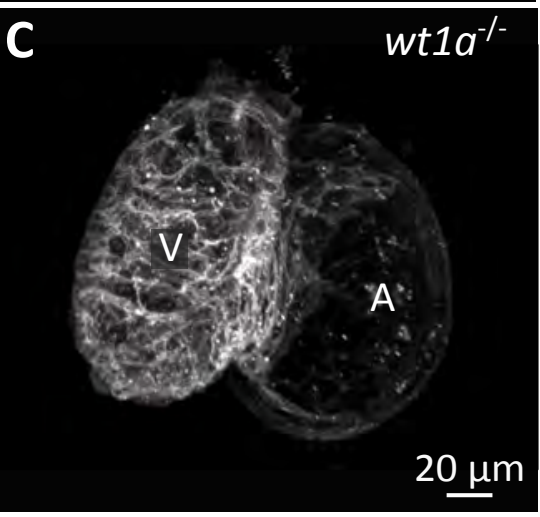

\section{D}

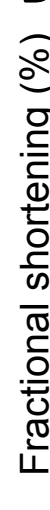

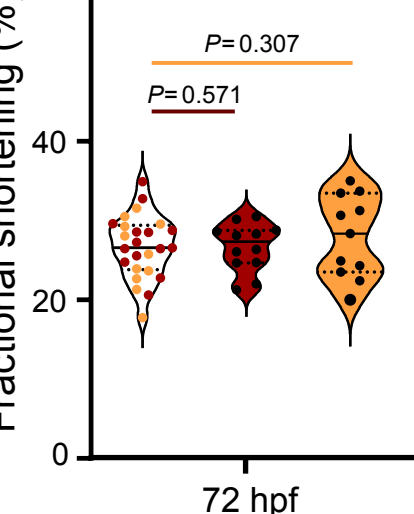

72 hpf

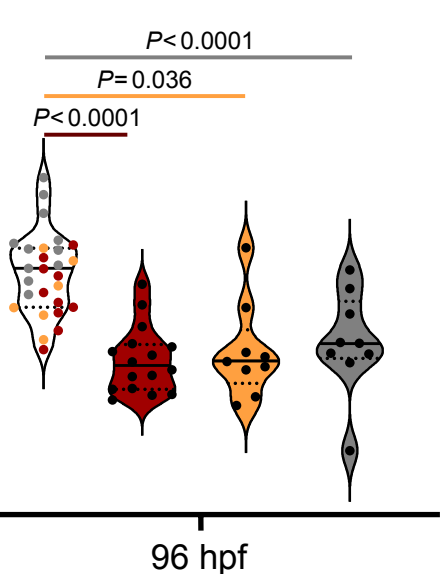

E

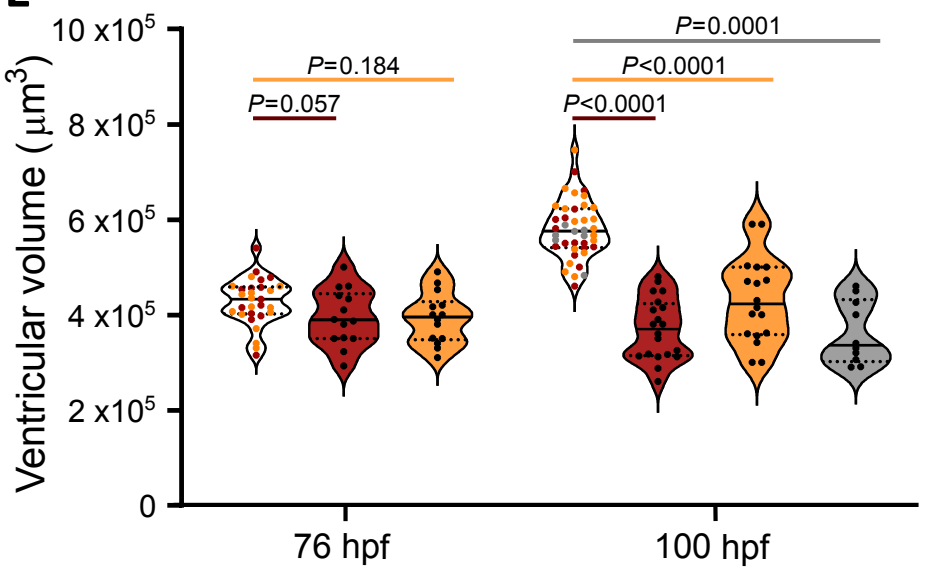

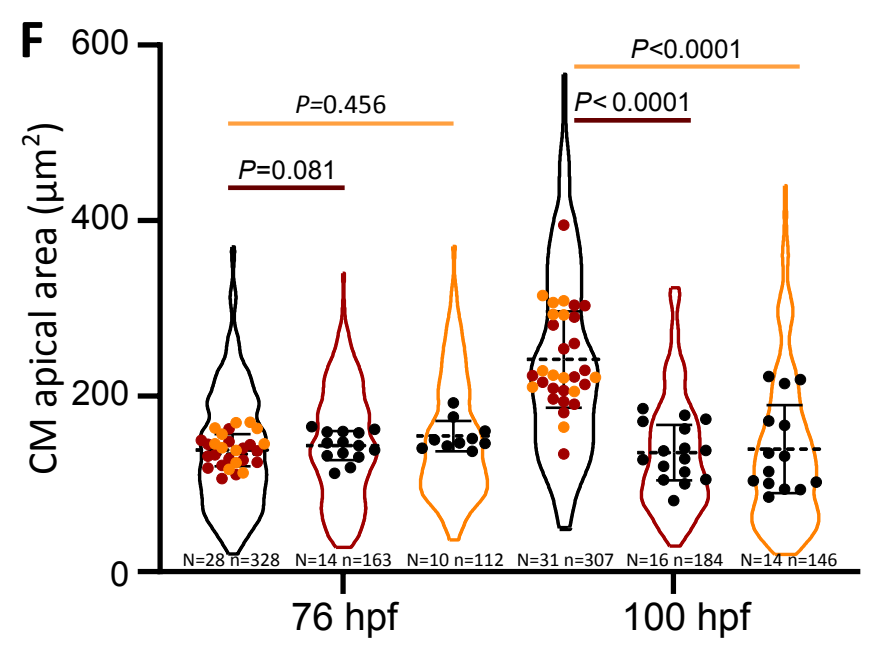
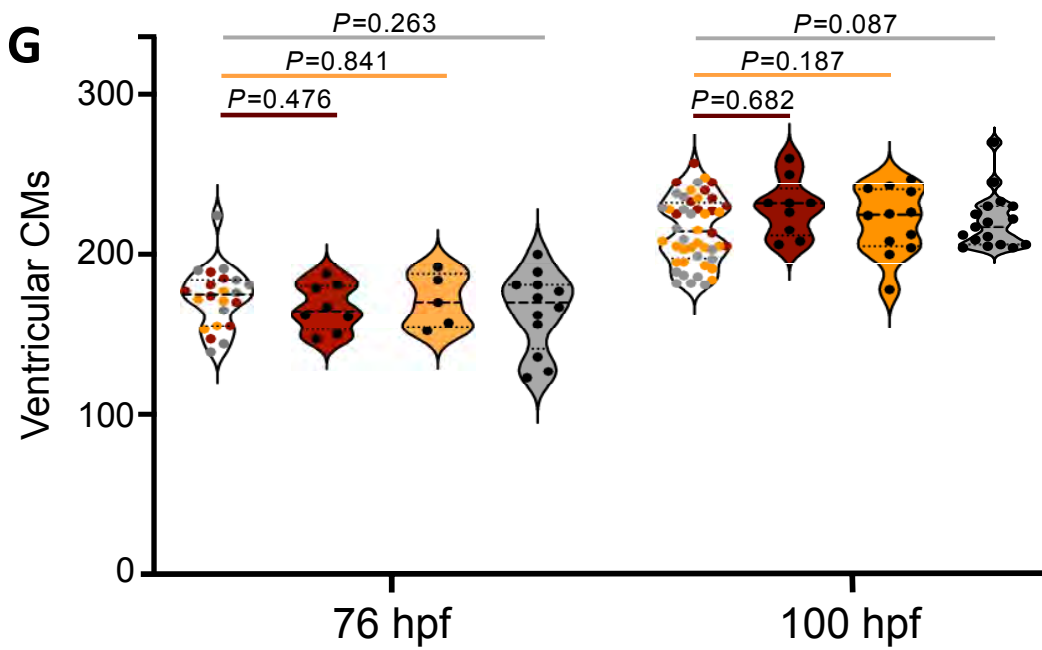

$76 \mathrm{hpf}$

100 hpf 
bioRxiv preprint doi: https://doi.org/10.1101/2021.08.09.455639; this version posted August 10, 2021. The copyright holder for this preprint

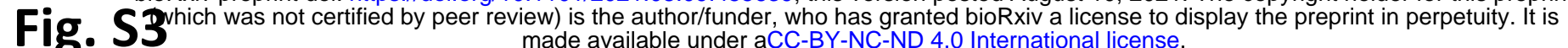
made available under aCC-BY-NC-ND 4.0 International license.
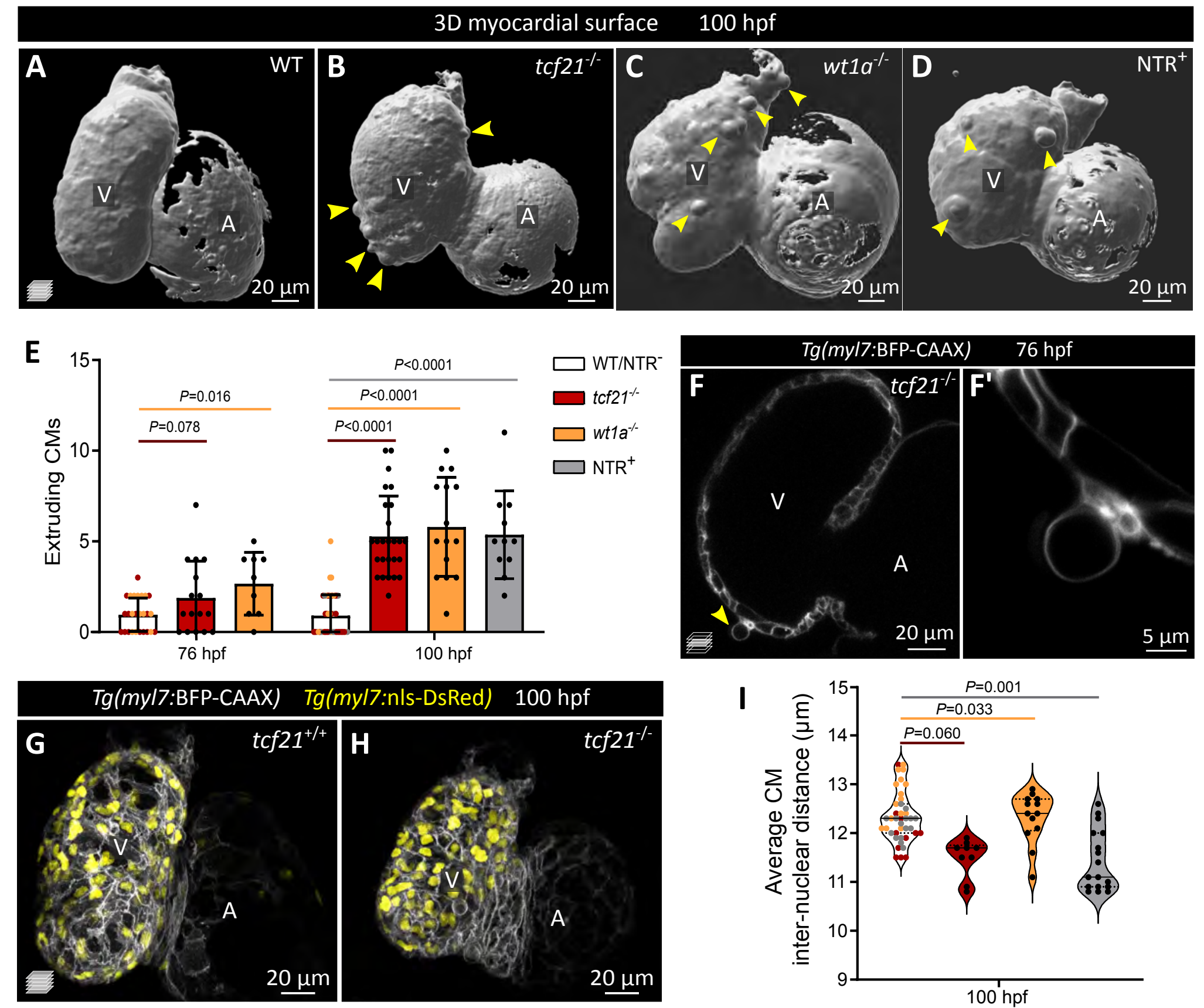

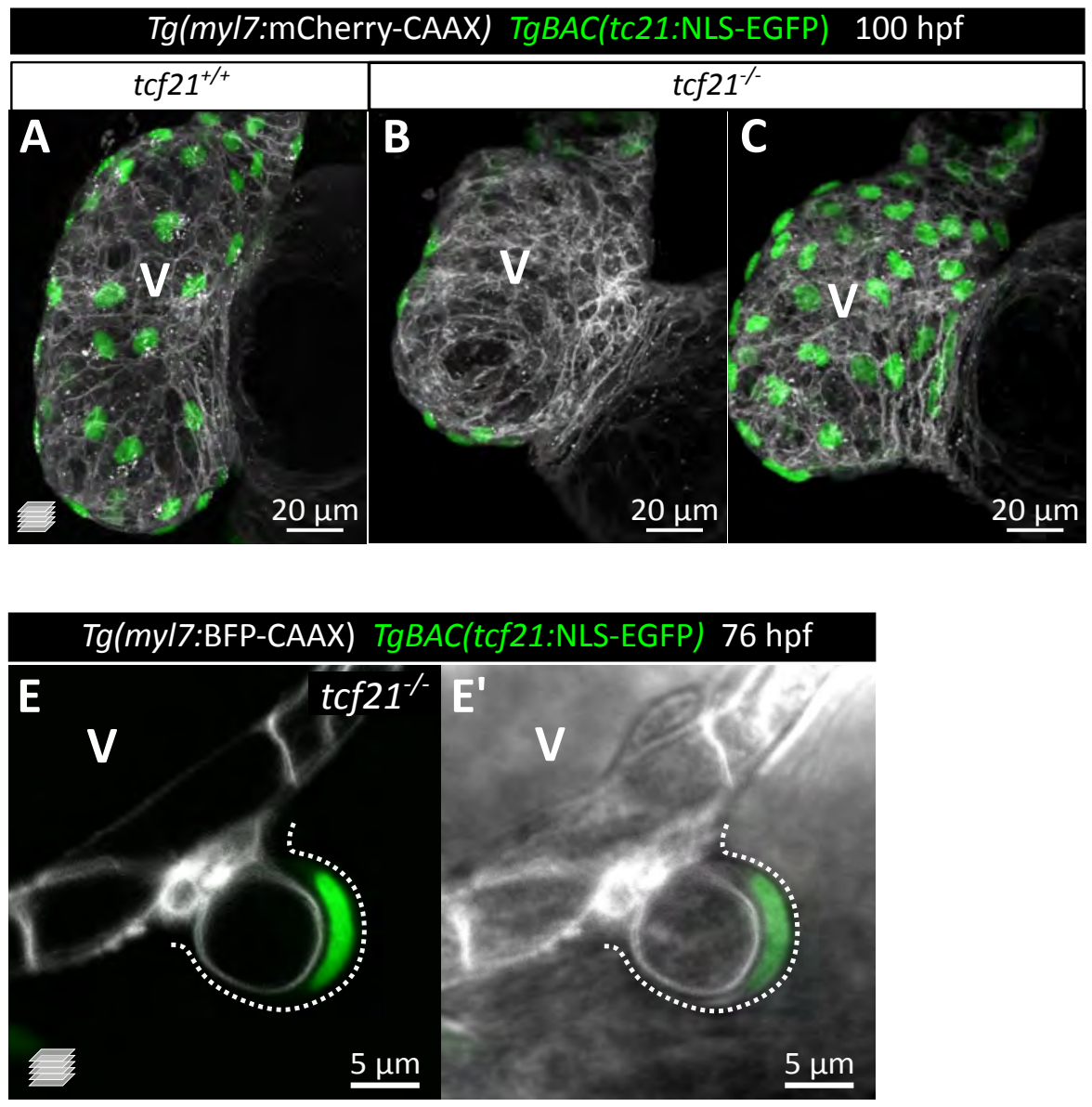
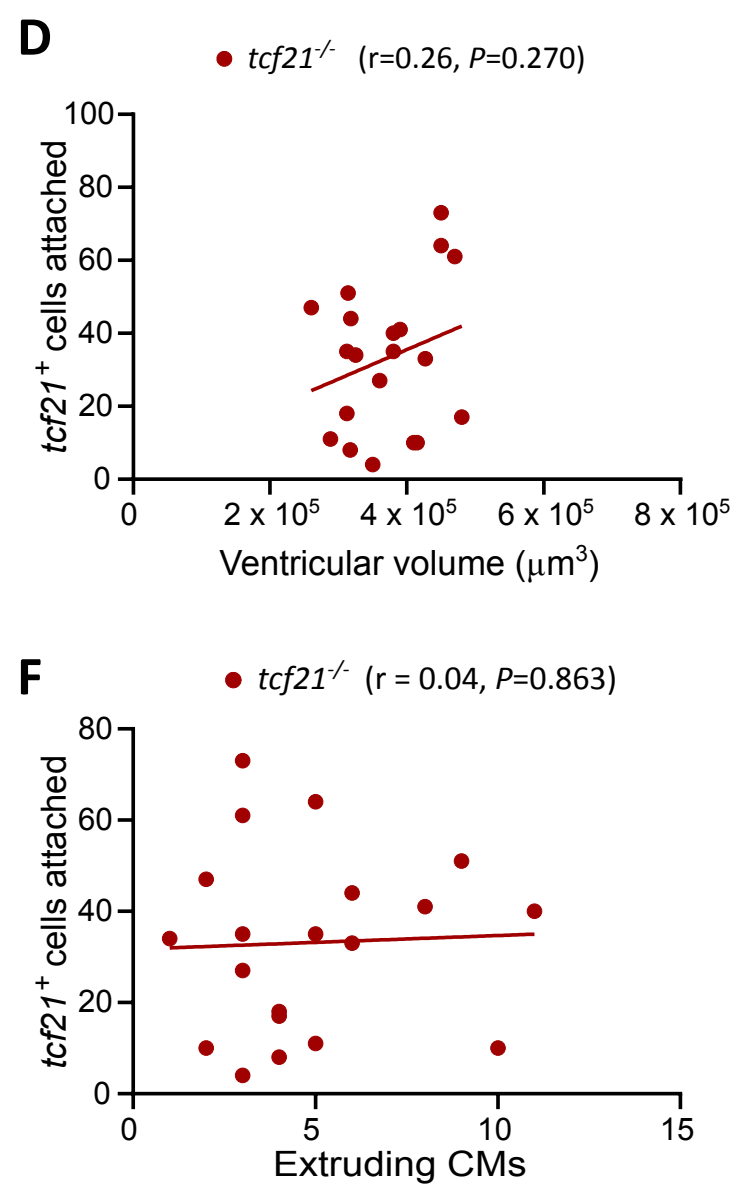
bioRxiv preprint doi: https://doi.org/10.1101/2021.08.09.455639; this version posted August 10, 2021. The copyright holder for this preprint

(which was not certified by peer review) is the author/funder, who has granted bioRxiv a license to display the preprint in perpetuity. It is

Fig. S5

A
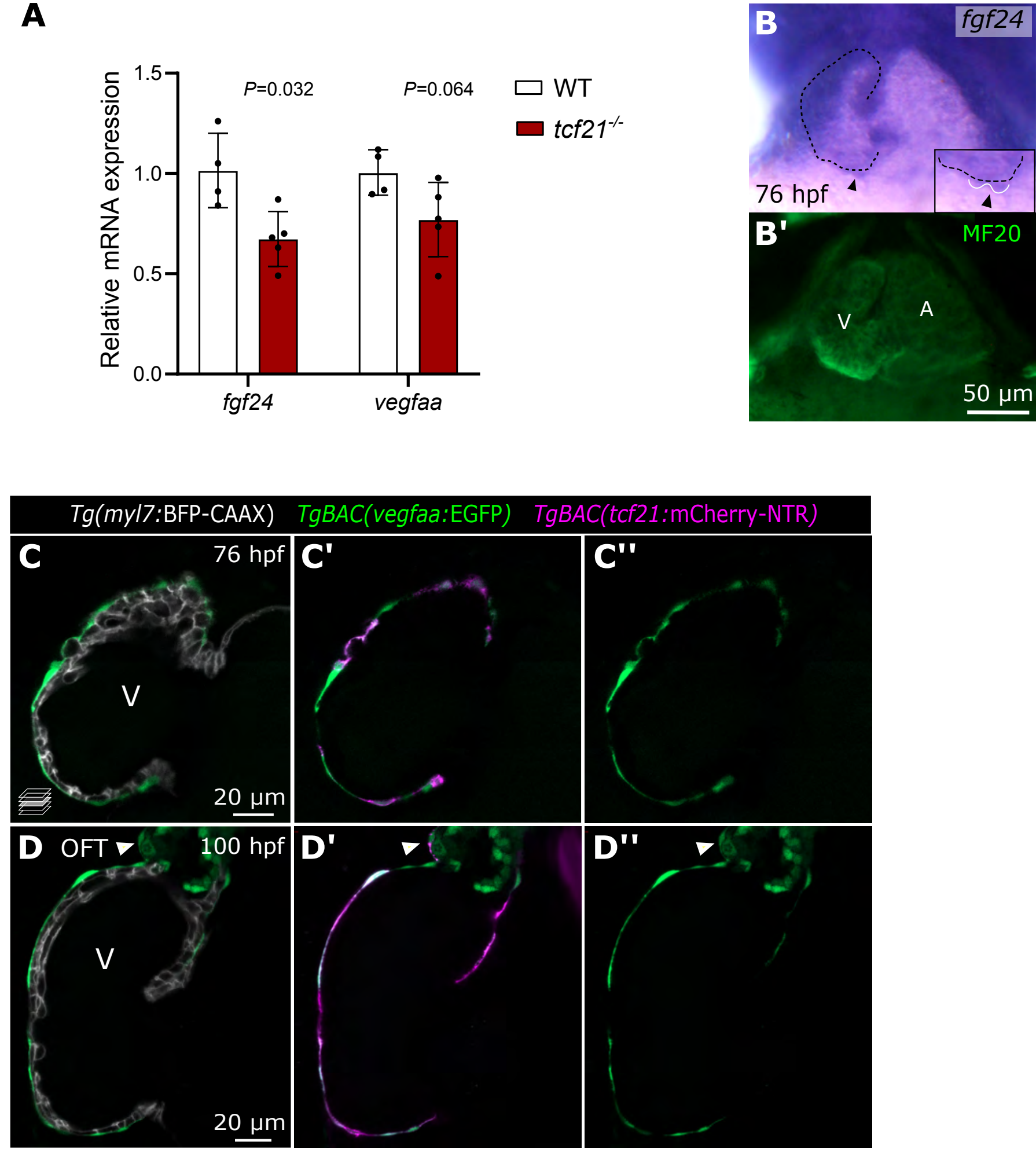